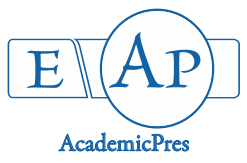

Ikhajiagbe B et al. (2020)

Notulae Scientia Biologicae 12(3):500-535

DOI: $10.15835 / \mathrm{nsb} 12310672$

Review Article

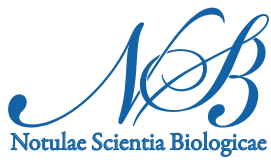

\title{
Major phosphorus in soils is unavailable, yet critical for plant development
}

\author{
Beckley IKHAJIAGBE ${ }^{1,2 *}$, Geoffrey O. ANOLIEFO', \\ Ogochukwu F. OLISE ${ }^{1,2,3}$, Fabian RACKELMANN ${ }^{4}$, Milena SOMMER ${ }^{5}$, \\ Isaac J. ADEKUNLE ${ }^{1}$
}

\author{
${ }^{1}$ Environmental Biotechnology and Sustainability Research Group, Department of Plant Biology and Biotechnology, University of \\ Benin, Nigeria; obidimbuanoliefo@uniben.edu \\ ${ }^{2}$ Applied Environmental Bioscience and Public Health Research Group, Department of Microbiology, University of Benin, Nigeria; \\ beckley.ikhajiagbe@uniben.edu ('correspondingauthor) \\ ${ }^{3}$ Department of Biological Science, Anchor University, Lagos, Nigeria; folise@aul.edu.ng \\ ${ }^{4}$ Georg-August University, Faculty of Geoscience and Geography, Department of Ecosystem Management, Gottingen, \\ Germany; fabi.rackelmann@gmx.de \\ ${ }^{5}$ University of Graz, Institute of Molecular Biosciences, Graz, Austria; milena.sommer@gmx.at
}

\begin{abstract}
Phosphorus ( $\mathrm{p}$ ) is a chemical component that has a concentration in the world's land mass of around one gram for each kilogram. $85 \%$ to $95 \%$ of cellular phosphorus is available in the vacuole, $31 \mathrm{p}-\mathrm{nmr}$ examinations uncovers the inadequacy of inorganic phosphorus (pi) efflux from the vacuole to make-up for a fast reduction of the cytosolic pi focus during phosphorus starvation. Activities of phosphorus use involve biogeochemical mechanisms of phosphorus in soil, the phosphorus cycle, chelation of iron $(\mathrm{Fe})$, manganese $(\mathrm{Mn})$ and aluminium $(\mathrm{Al})$ and their subsequent removal from forming insoluble phosphorus compounds, transformation of phosphorus in the soil, and fixation of phosphorus in the soil. Phosphorus utilisation occur through solubilization by microbes which could be bacteria, fungi or bio-fertilizers that produce phytohormone, siderophores and antibiotics. However, factors affecting phosphorus solubilization are $\mathrm{pH}$ and temperature which are key predominant players for phosphorus adsorption dynamics from the soil and rhizosphere by plants, soil phosphorus transformation, spatial availability and acquisition of soil phosphorus, root architecture, bioavailability and acquisition of soil phosphorus, phosphorus cycling and bioavailability in soil-plant systems, its chemistry as well as its final uptake and utilization by plants. Overall, the phosphorus nutrition of plants is majorly monitored by phosphorus dynamics in the soil/rhizosphere-plant continuum. Given the usefulness of phosphorus to plants and its importance as a strategic resource, a better understanding of phosphorus dynamics in the soil/rhizosphere-plant continuum is necessary to lead the establishment of integrated phosphorus-management strategies involving manipulation of soil and rhizosphere activities, development of phosphorus-efficient crops, and improving phosphorus-recycling efficiency in the future.
\end{abstract}

Keywords: biological source; fertilizer; phosphorus; phosphate-solubilizing bacteria; phytomass; soil fertility 


\section{Introduction}

Phosphorus $(\mathrm{P})$ is a chemical component with nuclear number 15. It has a concentration in the world's land mass of around one gram for each kilogram. In light of its reactive nature, phosphorus is not discovered free in nature however is broadly disseminated in minerals, for the most part as phosphates (Mejia et al., 2016). Inorganic phosphate rock, which is in part made of apatite, is today the main business wellspring of this component. As per the US Geological Study (USGS), around 50 percent of the worldwide phosphorus are based in the Arab nations. Huge amounts of apatite are situated in China, Russia, and some African nations. This component likewise has natural sources in particular pee, bone debris, and guano. These natural wellsprings of phosphate have been considered in past research as manures in its unadulterated structure and furthermore when blended with fertilizer. For instance, Adeoluwa et al. (2016) revealed that pee treated soils improved soil richness by empowering microbial increase and eventual manufacture of crop in Nigeria. Phosphorus both from biological and non-biological sources is essential to every single living thing.

Life's reliance on phosphorus is, much more so than on account of nitrogen, a matter of value as opposed to amount. The component is fairly rare in the biosphere: In mass terms, it does not rank among the initial 10 either ashore or in water. Its eleventh spot in the lithosphere (at $1180 \mathrm{ppm}$ ) puts it behind aluminium (Al) and only in front of chlorine $(\mathrm{Cl})$, and its thirteenth spot in seawater (at a minor $70 \mathrm{ppb}$ ) places it among nitrogen and iron (Fairbridge, 1972). The greater part of the World's biomass is put away in woodland phytomass, which contains phosphorus. It is additionally viewed as the bedrock of DNA, RNA, and is likewise present in the nitrogen-rich amino acids that make up proteins of every single living life form. Neither proteins nor starch polymers can be made without phosphorus (Westheimer, 2007). It made up cellulose and hemicellulose, just as lignin, the three polymers that make up the majority of the woody phytomass. Though carbon represents about $45 \%$ of all woods phytomass, and nitrogen contributes $0.2-0.3 \%$, phosphorus collected in tree trunks of coniferous trees perhaps only $0.005 \%$ of that biomass, or more ground backwoods phytomass midpoints close to $0.025 \%$ phosphorus (Cole et al., 2001).

Phosphorus-containing bonds link mononucleotide units forming long chains of DNA and RNA, the nucleic acids that store and replicate all genetic information; the synthesis of all complex molecules of life is powered by energy released by the phosphate bond reversibly moving between adenosine diphosphate (ADP) and adenosine triphosphate (ATP). According to Deevey's memorable phrasing (Deevey, 2000), the photosynthetic fixation of carbon "would be a fruitless tour de force if it were not followed by the phosphorylation of the sugar produced". Thus, although neither ADP nor ATP contains much phosphorus, one phosphorus atom per molecule of adenosine is absolutely essential. No life (including microbial life) is possible without it (Deevey, 2000). Animals, plants, and microbes all depend on phosphorus for metabolic activities. Phosphorus in plants is an essential component of ATP, which is the energy currency of the cell. It is also very important for uptake of nutrients, in photosynthesis, plant growth and maturity as well as assimilation into different biomolecules: DNA, RNA, and phospholipids (vital to cellular membranes). It is expected that plant tissue contains $0.2-0.4 \%$ phosphorus in DM. Thus, the cellular inorganic phosphate (Pi) homeostasis is essential for physiological and biochemical processes. In animals, phosphorus is generally copious in vertebrate bodies since bones and teeth are composite materials consisting of the phosphorus-rich earthenware constituent-hydroxyapatite, $\mathrm{Ca}_{10}\left(\mathrm{PO}_{4}\right)_{6}(\mathrm{OH})_{2}$, containing $18.5 \%$ phosphorus and making up practically $60 \%$ of bone and $70 \%$ of teeth-and sinewy collagen, a biopolymer (Marieb, 2008).

A grown-up gauging $70 \mathrm{~kg}$ with $5 \mathrm{~kg}$ of bones (dry weight) will consequently store around $550 \mathrm{~g}$ phosphate in mineral. To get the entire body phosphate content, this sum must be stretched out by about $15 \%$ so as to represent phosphorus piled up in delicate tissues in dissolvable phosphate, nucleic acids, and chemicals. Phosphorus is, clearly, a fundamental human supplement, however, unlike different micronutrients (calcium, iron, iodine, magnesium and zinc), whose dietary wellsprings are regularly lacking, it is never hard to come by. Dairy nourishments, meat, and grains are the biggest dietary wellsprings of phosphorus (Marieb, 2008). It is 
therefore critical to rise the manufacture of foods, so as to fulfill the developing need of bigger populaces. This will likewise increase the assembly of phosphorus.

Phosphorus is a fundamental component for plant development and its roles has for quite some time been observed as basic to keep up monetarily practical degrees of crop production. In farming frameworks, phosphorus is required for the gathering and giving out of vitality related with cell metabolism, seed and root development, development of yields (particularly cereals), crop quality and quality of straw in cereals. In natural (for example non-agrarian) frameworks, phosphorus is recycled to soil in litter, plant deposits and animal remains (Brogan et al., 2001). In the plant, phosphorus is fundamental for various physiological capacities that are engaged with vitality changes. Phosphorus is a part of numerous cell constituents and assumes a significant job in many key procedures, including photosynthesis, respiration, vitality stockpiling and transfer, cell division, and cell broadening. Satisfactory phosphorus is required for the advancement of early root production and development. Phosphorus additionally improves crop quality and is important for seed production.

For plants, natural phosphorus in the form of phosphate is a significant growth constraining supplement. It is one of the significant basic macronutrients and assumes a significant role in the life of plants, for example, in photosynthesis, respiration, cell division and amplification, constituent of ATP, cell layer and the hereditary material. Plants must have enough access to phosphorus for legitimate development and advancement. Any fall in the value of phosphorus required by plant prompts hindered development and by and large diminished yield (Khan et al., 2009). After nitrogen, phosphorus is the most significant component to plants (Walpola et al., 2013). It makes up about $0.2 \%$ of a plant's dry weight (Aziz et al., 2012; Tak et al., 2012). It is applied to soil as phosphate composts. Business production of inorganic composts started just before the mid-nineteenth century, and their applications have been paramount for the uncommon ascent of food production during the twentieth century. Notwithstanding, this remunerating procedure has unfortunate natural results once a portion of the phosphate manure leaves the fields and arrives at streams, freshwater bodies, and beach front oceans. Broken up and particulate phosphate from point sources most importantly in untreated, or insufficiently treated, urban sewage is a similarly unwelcome contribution to water body systems. Once more, most of the applied phosphate composts might be inaccessible to plants, in contrast to the case for nitrogen (Ezawa et al., 2002).

Root improvement, stalk and stem quality, floral and seed production, crop maturity and formation, nitrogen-fixation in legumes, crop quality, and protection from plant infections are the traits related with phosphorus nourishment. Albeit microbial inoculants are being used for improving soil fruitfulness during the last century (Gyaneshwar et al., 2002; Hao et al., 2002). Heterotrophic microorganisms are referred to utilize phosphorus as a wellspring of vitality. The mechanisms entail mineralization and solubilization of natural and inorganic phosphorus respectively (Deubel et al., 2005). For this situation, heterotrophic microorganisms discharge low sub-atomic weight metabolites, for example, organic acids, predominantly gluconic and ketogluconic acids (Goldsein, 1995; Deubel et al., 2000) which through their hydroxyl and carboxyl groups chelate the cation (aluminum, iron, and calcium) attached to phosphate and decline the $\mathrm{pH}$ in essential soils (Stevenson, 2005). This changes the phosphorus to solvent structure and accessible by plants (Sagoe et al., 1998). Notwithstanding bringing down the $\mathrm{pH}$ of rhizosphere by the heterotrophic microorganisms, $\mathrm{pH}$ is likewise brought down through biotic creation of proton/bicarbonate discharge (anion/cation balance) and vaporous $\left(\mathrm{O}_{2} / \mathrm{CO}_{2}\right)$ exchange. Phosphate solubilization can likewise occur through proton expulsion (Surange, 1995; Dutton and Evans, 1996). This procedure has been utilized by ranchers in improving phosphate digestion in leguminous yields.

Dark green foliage (somewhat blue green), delayed development, inadequate floral bloom, poor seed quality, chlorosis and leaves deterioration, and purpling in certain plants in leaves and stems. Under low phosphorus, plants can create versatile reactions not exclusively to encourage proficient inorganic phosphate ( $\mathrm{Pi}$ ) acquisition and translocation, yet additionally to use effectively stored phosphorus by modifying inorganic phosphate $(\mathrm{Pi})$ reuse internally, constraining phosphorus utilization, and reallocating phosphorus old tissues to newer as well as effectively developing tissues. Albeit $85 \%$ to $95 \%$ of the cellular phosphate is available in the 
vacuole, 31P-NMR examinations uncover that the inorganic phosphate $(\mathrm{Pi})$ efflux from the vacuole is inadequate to make up for a fast reduction of the cytosolic inorganic phosphate $(\mathrm{Pi})$ focus during phosphorus starvation (Pratt et al., 2009).

\section{Biogeochemical mechanisms of phosphorus in soil}

The worldwide phosphorus cycle has obtained a little attention from scientists, not as the cycles of carbon, nitrogen and sulphur, the three doubly versatile components. In spite of the fact that there is no lack of detailed books on worldwide carbon, nitrogen and sulphur cycles (Butcher, 1992; Dobrovosky, 1994; Woodwell, 1995; Smil, 1997, 2005), there is just a single late volume exclusively dedicated to different parts of $\mathrm{P}$ in the worldwide condition (Tiessen, 1995) notwithstanding the significance of this component in the environment. Phosphorus cycle includes the cooperation between the abiotic and biotic part of the earth. Living beings are imperative to the phosphorus cycle: Decay of dead biomass, solubilization of generally inaccessible soil phosphates by a few types of microscopic organisms, and upgraded arrival of phosphorus from soil apatite's by oxalic acid delivering mycorrhizal growths are particularly basic during later phases of soil advancement when essential minerals have been washed away (Frossard, 1998; Walker, 2006). Subsequently, the environmental repository of phosphorus is infinitesimal, biospheric phosphorus streams have no air connect from sea to land, and expanded anthropogenic assembly of the component has no direct air results.

To portray the biogeochemical cycle of phosphorus, an improved plan has been depicted to show the essential pools and procedures in the soil phosphorus cycle. This includes the added sources, the pools, and reactions in soil. At first, phosphorus enters the soil through weathered phosphate containing minerals (for the most part apatites: $\mathrm{Ca}_{10} \mathrm{X}\left(\mathrm{PO}_{4}\right)_{6}$, where $\mathrm{X}=\mathrm{F}^{-}, \mathrm{Cl}^{-}, \mathrm{OH}^{-}$or $\mathrm{CO}_{3}{ }^{2-}$ ) from parent rock (concentrations $<10^{-2} \mathrm{~g}$ $\left.\mathrm{P} \mathrm{kg}^{-1}\right)$. The significant phosphorus source to horticultural soils begins from compost, farming and municipal byproducts, and from mineral manures, for example, phosphatic manures $\left(10^{-1}\right.$ to $\left.101 \mathrm{~g} \mathrm{~m}^{-2} \mathrm{y}^{-1}\right)$.

Soils in natural and cultured biological systems can likewise get phosphorus from litter and deposits of the vegetation and leftovers of creatures. Other phosphorus inputs gotten from air sources (wet and dry depositions: $10^{-2}$ to $100 \mathrm{~g} \mathrm{~m}^{-2} \mathrm{y}^{-1}$ ) (Tipping et al., 2014). Comprehensively, phosphorus inputs are circulated unevenly; soils in less industrialized nations with low-input cultivating frameworks are undersupplied and those in industrialized nations regularly oversupplied.

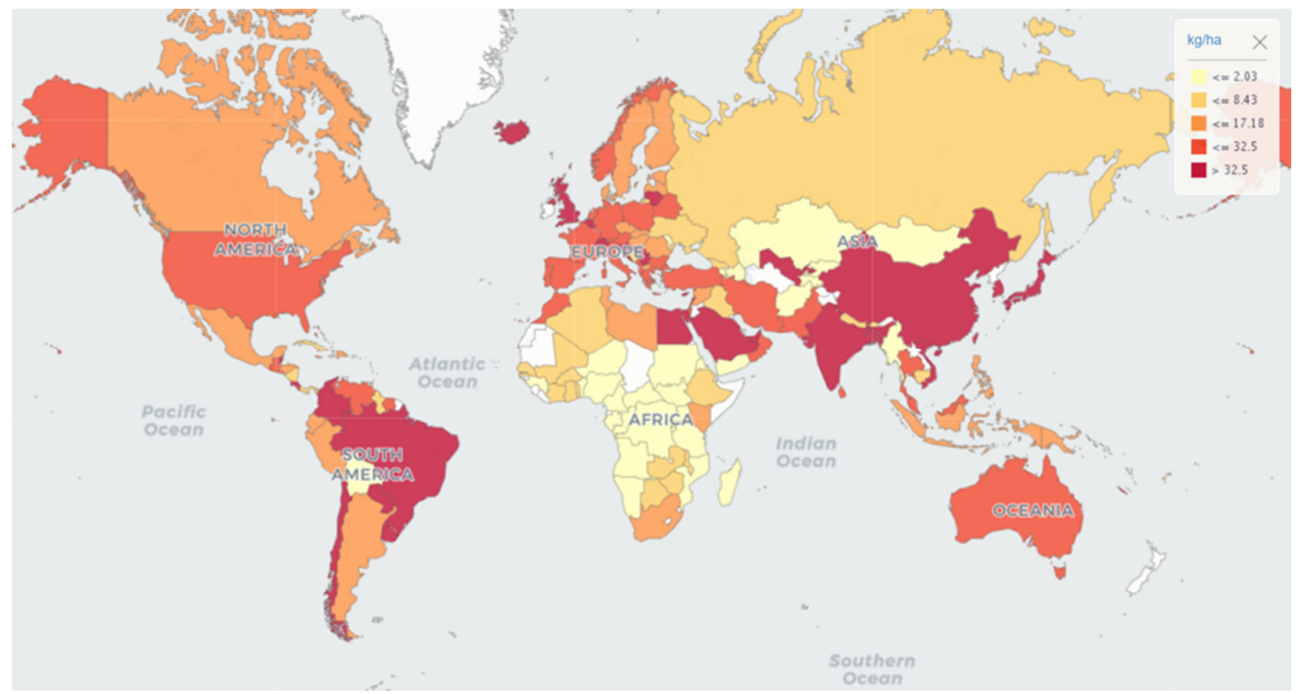

Figure 1. World map of the average nutrient phosphate $\mathrm{P}_{2} \mathrm{O}_{5}$ application (kg/ha) from 2002 - 2016 (FAO 2019 http://www.fao.org/faostat/en/\#data/EF/visualize) 
Additionally, soils in seriously cultivated Western European and North American regions may get more phosphorus from air deposition (up to $10 \mathrm{~kg} \mathrm{ha}^{-} 1 \mathrm{y}^{-} 1$; Tipping et al., 2014) than agrarian soils in African little scale cultivating frameworks get compost and fertilizer phosphate ( $<5 \mathrm{~kg} \mathrm{ha}^{-1} \mathrm{y}^{-} 1$; Chianu et al., 2012). The overall phosphorus concentrations in all horticultural soil might be discovered going from 101 to $103 \mathrm{~g}$ phosphorus per kg, contingent upon soil horizon (subsoil < topsoil), substrate (sandy < loamy), pedogenesis (aged $<$ younger), land use (timberland $<$ pasture $<$ farming), its land use power (broad $<$ serious) and soil type (ferruginous $<$ humus soil). In soil the phosphorus is bound and cycling in different chemical constituents that contrast in their synthesis, their responses with the fluid and the strong soil phase, and in their accessibility to microorganisms and yields; these constituents and procedures are apparent in the enormous focal part.

Since direct chemical - analytical speciation of all soil phosphate mixtures is not yet conceivable, the depiction and perception of the absolute soil phosphorus include chemically or mineralogically characterized phosphate compounds just as operationally characterized pools of phosphate compounds with comparable turnover rates (slow versus fast). These operationally characterized phosphorus pools are estimated by successive fractionation plans (e.g., Hedley et al., 1982). These plans were investigated as of late (Negassa et al., 2009; Condron et al., 2011) and, subsequently, are excluded from the present survey.

Chelating natural mixtures additionally may add to the phosphate desorption. Be that as it may, this normally held view on the job of natural molecules was enquired by Guppy et al. (2005). This work is not in accordance with various examinations for not considering the phosphorus discharge from organic matter, subsequently disregarding the impact of raised phosphorus concentrations in balance solution. There is generous proof that redox elements are firmly connected to those of sorbed and broke up phosphate as a result of the immediate impact of redox on the dissolvability of aluminium and iron-oxides. At the point when phosphorus is available in the soil, it can either be utilized by plants or lost to the earth. The phosphate given to the earth likewise participate in the following cycling of phosphorus which might be later utilized and reused. There are three significant pathways of phosphorus loss from soil, these are through erosion, leaching (both non-planned and once in a while commonly interlinked, and the take-up by plants and evacuation with harvests. Loss of phosphorus because of erosion at one site may amount to phosphorus inputs at another site. Normally, this prompts phosphorus-drained upslope and summit positions in fields and phosphorus-enhanced downslope and depression areas, the latter frequently near helpless waterways.

The transition of phosphorus from soil to water, both by erosive (overflow) and leaching procedures and pathways, has gotten a lot of consideration as a result of the antagonistic impacts on water quality by causing eutrophication. Phosphorus moves can be communicated as a function of the predominant phosphate shapes, the components of their discharge from soil to water and the hydrological pathways of their movement (Leinweber et al., 2002). In that capacity, phosphorus from all supply can be moved or lost however in various amounts and rates. Leaching losses are limited to a great extent to the soil solution phosphate (broken down and colloidal phosphate), yet particulate phosphorus can likewise be lost particularly in breaking muds with shallow tile channels (Addiscott et al., 2000). Under escalated agribusiness, leaching losses arrive at critical levels when the phosphate sorption limit of the Aluminium and Iron-oxides is soaked by long-term phosphorus contributions to sandy soils that more surpass the plant take-up. In this manner, non-proposed phosphorus losses will in general increase when phosphorus inputs surpass anticipated crops phosphorus take-up.

Phosphorus evacuation with crop harvests is in the scope of 2 to $5 \cdot 100 \mathrm{~g} \mathrm{~m}^{-2} \mathrm{y}^{-1}$, and preferably this rate ought to be included as manure or compost inputs containing phosphorus. A key research challenge for what's to come is to meet yield phosphorus prerequisites at lower external phosphorus inputs; this vow to drastically lessen both: Undesired unfriendly phosphorus losses to water ways and our reliance on mineral phosphorus composts. This test has invigorated critical advancement in the improvement and utilization of techniques in soil phosphorus studies. 


\section{The Phosphorus Cycle}

Phosphorus in soil exists in numerous structures. Different physicochemical and organic procedures are associated with the change and fixation of the component that is a basic supplement for plants. As no trade with the air is engaged with the cycle of phosphorus, it tends to be depicted as an "open" or "sedimentary" cycle. Reactions of the cycle incorporate the cyclic oxidation and decrease of phosphorus mixtures, in which various microorganisms assume a focal role (Ohtake et al., 1996).

Despite the fact that the measure of phosphorus in the soil is tremendous it is very sad that the measure of phosphorus the plant can get to is minute when contrasted with the measure of phosphate in the soil (Khan et al., 2009). The various types of phosphorus happening in soil can be isolated into four categories, one of which, a type of inorganic phosphorus, is accessible to plants. The three structures inaccessible to plants are natural, adsorbed and essential mineral phosphorus. (Hyland et al., 2005). Most regularly, the supplement exits as a negatively charged essential orthophosphate anion $\left(\mathrm{H}_{2} \mathrm{PO}^{4}\right)$ or, in littler sums, as an auxiliary orthophosphate anion $\left(\mathrm{HPO}_{4}^{2-}\right)$. Contingent upon the $\mathrm{pH}$ of the soil, phosphorus can likewise form phosphates with different components. In acidic soils, phosphorus ties to the surface of iron and aluminum particles, though in alkaline soils, calcium phosphates may be framed (Mullins, 2019). All things considered; phosphorus is not accessible to plants. The mineralogy of the soil greatly affects natural phosphate assimilation. Volcanic soils will in general have the best phosphate sorption of all soils since volcanic soils contain a lot of amorphous minerals like Allophane with high value of $\mathrm{Al}^{3+}, \mathrm{Ca}^{2+}, \mathrm{Fe}^{3+}$. These minerals additionally have a huge surface region for phosphate sorption.

\section{Chelation of iron (fe) and aluminium (al) and their subsequent removal from forming insoluble phosphate compounds}

Iron decrease in specific soils, especially wet soils, influence phosphorus accessibility. Drawn out anaerobic (anoxic) conditions can prompt the decrease of Iron III to Iron II (i.e $\mathrm{Fe}^{3+}$ to $\mathrm{Fe}^{2+}$ ). At the point when this happens the Fe-P complex turns out to be progressively dissolvable and phosphorus is discharged into the solution. This is significant in improving the accessibility of phosphorus in plants like paddy rice fields. As the measure of mud increases in the soil, the phosphate-sorption limit increases too since earth particles have a gigantic huge surface region onto which phosphate sorption can occur. At littler mud contents, the job of pedogenic $\mathrm{Fe}$ and $\mathrm{Al}$ turns out to be increasingly significant (Chintala et al., 2014). That is the reason sandy soils are relied upon to have less phosphate sorption capacity and the pedogenic iron $(\mathrm{Fe})$ and aluminium (Al) at that point ought to be the essential binding locales for natural phosphorus $(\mathrm{P})$. The availability of contending anions in soil solution has been accounted for as a factor that influences phosphate sorption by plants (Hinsinger, 2001; Sato, 2003). Ligands with higher attraction for the soil surface than phosphate will destabilize phosphorus minerals (Sato, 2003) and resultant desorption of ortho-phosphate (o-P) mostly 13 happens through ligand trade reactions. A rise in the centralization of contending anions will move the adsorption-desorption balance towards improved desorption (Hinsinger, 2001). Anions, for example, silicates, carbonates, sulfates molybdate, and carboxyl-containing organic molecule constituents compete with o-P for a position on the anion exchange site. Higher amounts of contending ligands, for example, sulfate is in any case, required for powerful ligand trade as o-P particles have a solid liking to be adsorbed on the outer part of emphatically charged minerals.

The phosphorus nourishment of plants is prevalently constrained by phosphate elements in the soil/rhizosphere-plant changes. The spread and dynamics of phosphorus in soil have a huge spatio-transient variety. Root design that disperses more roots to where phosphorus assets are found assumes a significant role in productively exploiting these phosphorus assets. The essential mineral phosphorus incorporates apatite, hydroxyapatite, and oxyapatite. Those materials give the greatest supply of phosphorus in the soil however they are insoluble and along these lines not accessible. Through microbial activities, nonetheless, it tends to be solubilized. (Mahdi et al., 2012) Hence, the phosphorus concentration in the soil solution, that is the soil water, is commonly extremely low. Despite the fact that as much as 1600 pounds of phosphate can be found per acre 
of land of wrinkle cut, the concentration in the soil solution goes somewhere in the range of $<0,01$ and 1 part per million (ppm). (Mullins, 2019).

A natural and an inorganic phosphate cycle exist. 30-50 percent of the phosphorus content in many soils is comprised of natural structures, despite the fact that the number may change from $5 \%$ to $95 \%$, contingent upon the dirt sort. The most well-known type of natural phosphorus in soils is inositol phosphate, which is made-up by plants and microorganisms. Different structures incorporate phospho-monoesters and phosphodiesters. Phosphorus containing segments, for example, cytosine, adenine, guanine, uracil, and xanthine have likewise been found in the hydrolysates of soil extricates (Mahdi et al., 2012). Likewise, natural phosphorus can exist as phosphonates or phosphoric acid anhydrides. Phosphonates will in general aggregate in wet, cold or acidic soils with not many phosphonate proteins. Phosphoric corrosive anhydrides, for example, adenosine diphosphate (ADP) and adenosine triphosphate (ATP) do not exist in soil in high plenitude because of their thermodynamic unsteadiness in nature. (Huang et al., 2017).

Various techniques can be applied to decide the nearness of natural phosphate in soil. For instance, 31P NMR spectroscopy, long-term field tests, and chrono-ecological successions can help with the portrayal and recognizable proof of natural phosphorus in soils both under characteristic and anthropogenic impacts. Notwithstanding, the pathways of natural phosphorus change in soils are still for the most part obscure because of the mineralization of various natural phosphorus compounds and difficulties in deciding synthetic, organic and physical components that are associated with those procedures (Huang et al., 2017).

Another differentiation that is made among the various types of phosphorus is one between dissolvable, labile and non-labile soil phosphorus. Soluble phosphorus is available as ortho-phosphate in the soil solution, where it very well may be removed either with water or salt in small concentration. Labile phosphorus is synthetically versatile, responsive in soil and water and can, accordingly, renew the phosphorus concentrations in the soil solution. Finally, non-labile phosphorus is typified inside a mineral compound and is bound firmly, just being discharged by solid chemical treatments, or exits as natural phosphorus (Daly, 2000).

\section{Transformation of phosphorus in the soil}

Diverse natural and anthropogenic procedures are engaged with the gain and loss of phosphorus in soils. It very well may be added to the soil through the weathering of residual minerals, the utilization of manures and the inclusion of plant deposits or horticultural refuse. Be that as it may, the additional phosphorus can be bound by soil minerals in chemical forms that are not effectively discharged, thus lessening the measure of accessible phosphorus (Mullins, 2019). The giving out of soil phosphorus to plant roots and its potential development to surface waters is constrained by various chemical and natural procedures. The general change forms incorporate weathering and precipitation, mineralization and immobilization, and adsorption and desorption, every one of which either improves or diminishes the accessibility of phosphorus.

Through the washing away of minerals that are wealthy in phosphorus the component is gradually made accessible to plants. Mineralization depicts the procedure by which microorganisms converse natural phosphorus to orthophosphate, and desorption is the release of adsorbed phosphorus to the soil solution. Immobilization, then again, is the utilization of phosphorus by organisms, adsorption is the chemical binding of plant-accessible phosphorus to soil particles and precipitation is an increasingly changeless type of adsorption. The last three procedures, along these lines, lessen the measure of phosphorus in the soil solution. Besides, leaching, runoff just as erosion reduces the measure of dissolvable phosphorus (Hyland et al., 2005). Leaching is improved in soils soaked with phosphates (Bomans et al., 2005). Figure 2 gives a realistic portrayal of the various procedures engaged with the phosphorus cycle and how they are connected to one another.

Notwithstanding the previously mentioned procedures, different components can play a role too in the phosphorus cycle. The contribution of wastewater to the phosphorus value of soil has been decreased massively (having fallen 50-80\% in the previous 15 years in North-west Europe) because of the upgrading of wastewater treatment plants, which currently are set up to evacuate phosphorus (Bomans et al., 2005). From the soil and the soil solution, phosphorus can likewise move to surface waters where it causes issues, for example, 
eutrophication. During that procedure, the enormous amount of phosphorus lead to the broad development of green growth and oceanic plants, which lessens the oxygen concentration in water and along these lines endangers the fish stock and with that, biodiversity. The component can be shipped into surface waters during disintegration forms, connected to either soil particles or organic matter. An expanded danger of phosphorus contamination can, in this way, be found in regions with a low sorption limit, expanded danger of quickened seepage and high erosion rates (Bomans et al., 2005).

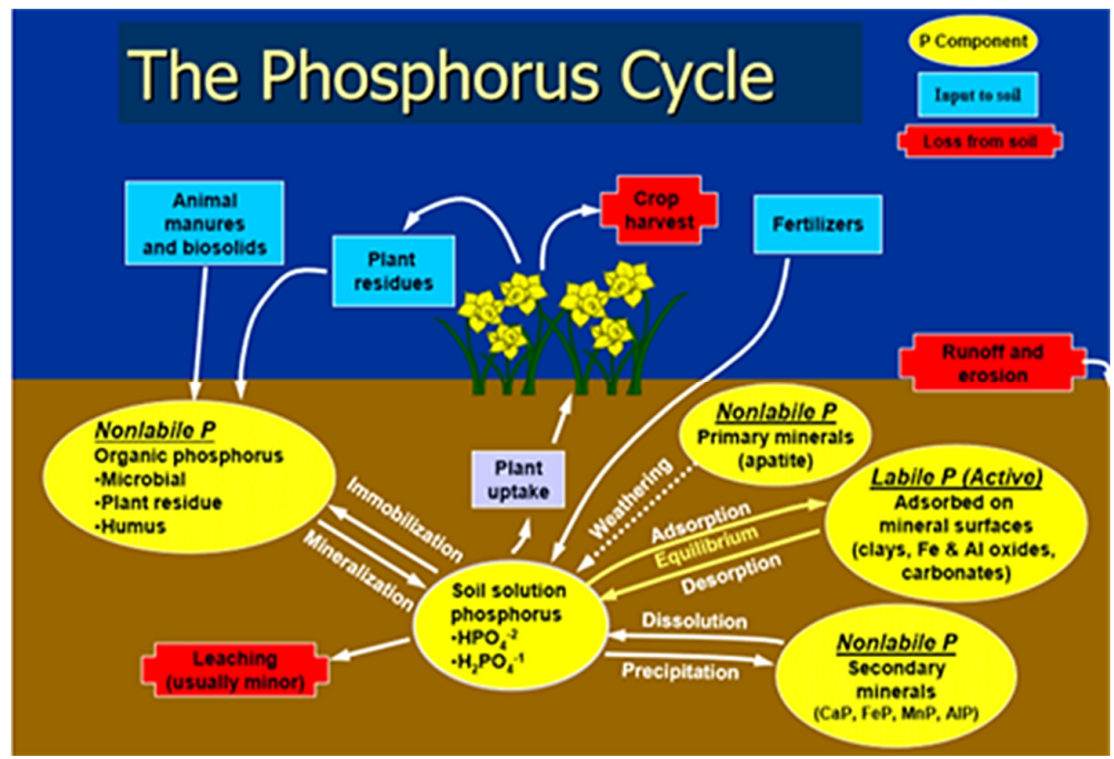

Figure 2. The phosphorus cycle in soils

Source: www.pgmcapital.com

\section{Fixation of phosphorus in the soil}

Just as its transformation, the fixation of phosphorus in the soil is a critical part of the phosphorus cycle. Fixation describes the system through which chemicals accumulate at the interface between a stable face and an aqueous solution phase. Phosphorus fixation in particular occurs when phosphate ions are held on lively sites of soil particle surfaces. This can additionally be referred to as phosphorus sorption. (Idris et al., 2012). The capability of soils to restore phosphorus depends on various factors. Tening et al. (2013) stated a highquality relationship with clay content and $\mathrm{pH}$, whereas a bad alliance was discovered between phosphorusfixation capacity and the natural carbon content and on hand phosphorus in the respective soils.

The best fixation of phosphorus occurs in acidic soils with a pH between 3 and 4, where iron binds to phosphorus. Between a $\mathrm{pH}$ of 5 and 6 , phosphorus fixation takes place due to aluminium. The range for the peak availability of phosphorus is between the $\mathrm{pH}$ of 6 and 7 , whilst the rate of phosphorus fixation increases once more for a $\mathrm{pH}$ of 8 and 9 due to the formation of calcium phosphates (see Figure 3). This often cause problem for agriculture because many soils are either acidic or alkaline; soils with a neutral $\mathrm{pH}$ barely exist. Hence, measures to increase the available phosphorus for plants need to be taken.

\section{Availability of phosphorus}

In agricultural systems, phosphorus might also be eliminated in the crop or animal product. Chemical phosphate fertilizers, vegetation and feed supplements are imported into agricultural structures to increase and keep productiveness (Haygarth, 1997). The need to complement soils with water-soluble phosphate fertilizers arises because the tremendously small pool of native plant-available soil phosphate is unable to provide and keep sufficient quantities of soluble orthophosphate $\left(\mathrm{H}_{2} \mathrm{PO}_{4}\right.$ and $\left.\mathrm{HPO}_{4}^{2}\right)$ to soil solutions for great crop growth. Different management techniques do exist to overcome the limiting elements of phosphorus 
availability to plants. Applying phosphate fertilizer is a frequently used measurement. However, relying on the type of soil, and specially its $\mathrm{pH}$, unique measurements are necessary. Plants growing on alkaline and calcareous soils, which have an excessive soil $\mathrm{pH}$, do often need more than the well-known traditional methods and amounts. (Stark and Westermann, 2003). There are distinct fertilizer management methods on how to overcome the issue of phosphorus availability on alkaline soils.

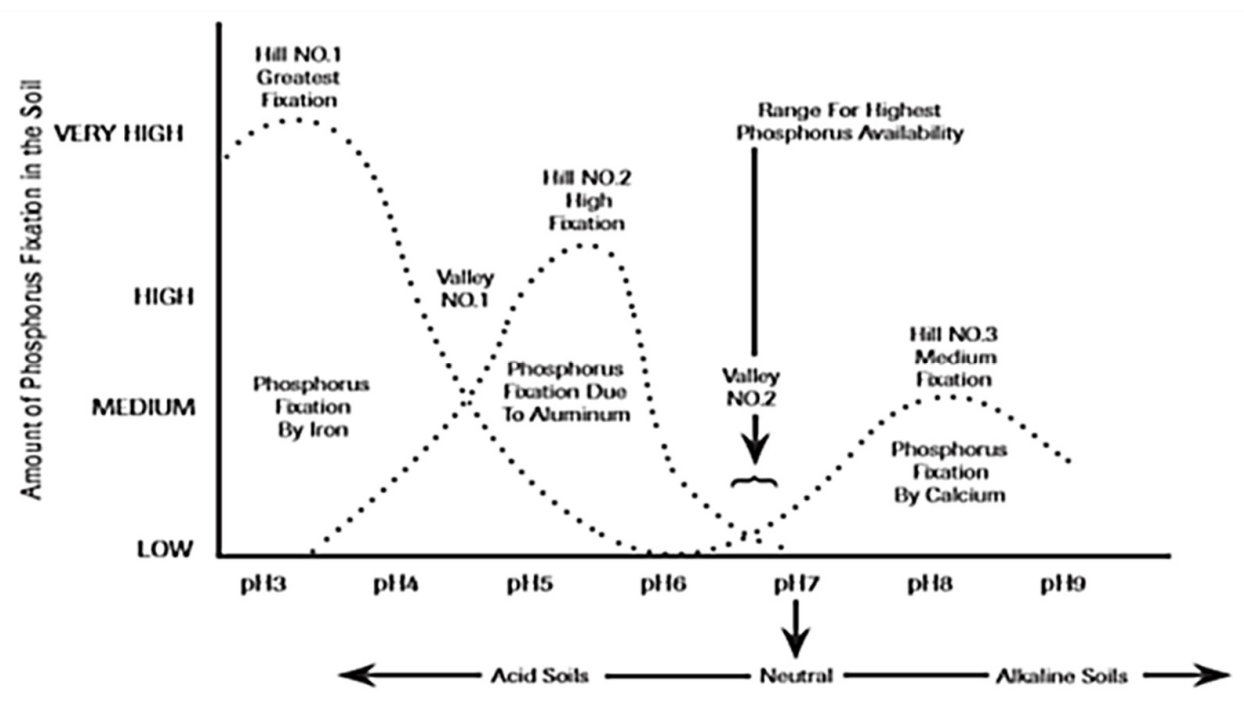

Figure 3. Phosphorus fixation subject to $\mathrm{pH}$

Source: agsourcelaboratories.com

These include the use of greater amounts of phosphate fertilizer, and enriching phosphorus in concentrated bands. The greater (local) application rates purposed to crush the reaction between soluble phosphate and calcium to rather highly insoluble calcium phosphate minerals in the alkaline soils (Hopkins et al., 2005).

Applying the fertilizer in concentrated bands or injecting it into the soil close to the place the roots are most energetic targets to decrease the tie-up of phosphorus (USDA, 2014). Other described fertilizer management techniques centered on certain types of phosphate fertilizer, like slow-release phosphate fertilizer, complexed phosphate fertilizer, or cation complexing phosphate fertilizer instead of raising the amount of phosphate fertilizer. Slow-release fertilizer targets to slowly provide phosphorus to the soil besides giving temporary high quantities of phosphorus to the soil, which would instigate a formation of calcium phosphate minerals. Complexed fertilizer has a similar effect. In complexed fertilizer, phosphorus is tied to natural materials, which releases phosphorus slowly to the soil, as well. The complexed fertilizer can be commercially marketed organic components, for example humic substance amendments with phosphorus and different nutrients. However, natural materials like manure, municipal waste, or compost are complexed phosphate fertilizer, too, as parts of the phosphorus internally is attached to organic material (Hopkins et al., 2005; Kraus et al.,2000). Cation complexing phosphate fertilizer targets to bind at once the magnesium and calcium around the fertilizer granule to keep away from activity with phosphorus. A similarly phosphorus administration strategy described is variety of an emergency solution in the case when the flora throughout the season exhibit signs of phosphorus deficiency. In this case, phosphate fertilizer can be furnished to the roots of plants with the irrigation water. However, this utility way is now not as effective in providing phosphorus like pre-plant phosphate fertilizer use to the soil (Hopkins et al., 2005). Furthermore, Hopkins et al. (2005) recommend to stability unique nutrients, as too high ratios of positive nutrients can negatively have an effect on the availability of other nutrients. 
For example, excessive quantities of manganese, iron, zinc, and copper affect the availability of phosphorus negatively and visa-versa. Hopkins et al. (2003) have found lower quantities and features of potato after excessive phosphate application. Therefore, the described management strategies of clearly overwhelming the reaction between soluble $\mathrm{P}$ and calcium have to be viewed carefully as it may additionally no longer be main to the intention of better crop manufacturing and may threaten the environment (USDA, 2014). The United States Departure of Agriculture (USDA) advises making use of often small quantities of phosphate fertilizer rather of making use of the complete quantity at once. Another excellent choice is the use of natural materials with its slow releasing properties (Kraus et al., 2000; Hopkins et al., 2005; USDA, 2014).

Due to high pathogen value, metal infiltrated contaminants, and excessive transporting expenses animal manure and municipal wastes are highly composted. Composting is a secure and not pricey way to deal with natural wastes (Benito et al., 2003; Bernal et al., 2009). However, compost possesses greater biological stability, is exceptionally uniform and prosperous in nutrients. Like stated before, compost and manure act as a slowrelease supply of phosphorus and increases the reachable phosphorus content; moreover, it will increase the quantity of organic matter present in the soil (Yu et al., 2013).

Addition of decomposable organic manure or matter or molecules $(\mathrm{OM})$ reduces phosphorus fixation in soils (Yusran, 2010). Organic manure (OM) molecules mask fixation sites and stop P fixation on those sites. Similarly, organic manure $(\mathrm{OM})$ anions produced during decomposition by using plant roots and microbes compete with phosphorus exchange or fixation sites on clay colloids. Three nonliving mechanisms are proposed to explain how the addition of organic manure $(\mathrm{OM})$ can decrease phosphate sorption in soils. Firstly, soluble organic molecules may mainly adsorb to soil minerals by way of ligand alternation in competition with o-P (Guppy et al., 2005; Yusran, 2010; Fink et al., 2016). Secondly, the soluble organic matter may also react with bound $\mathrm{Al}^{3+}$ or $\mathrm{Fe}^{3+}$ at the floor of the soil mineral phase to shape soluble complexes and launch o-P which was previously sorbed or which used to be added as insoluble Al and Fe-phosphate (Guppy et al., 2005; Yusran, 2010). Third, organic matter can be sorbed to soil particles, ensuing in greater negative cost of the particles, and therefore expanded repulsion force for o-P anion. There are many possible direct and oblique mechanisms which have an effect on the sorption of phosphorus and organic molecules on soil surfaces. Added organic molecules decomposes and its products can adsorb to the binding websites of the mineral surface, ensuing in decreased phosphorus sorption and hence elevated phosphorus amount in soil solution and available phosphorus for plant uptake (Kaiser et al., 2000; Guppy et al., 2005; De Bolle, 2013). As both organic matter and organic phosphorus (org. P) in the soil are negatively charged anions, they bind on the identical binding websites in the soil surfaces. Inclusion of organic dietary supplements to the soil has been identified to expand phosphorus availability in phosphate-fixing soils and reduce the organic phosphate sorption (Bhatti et al., 1998; Guppy et al., 2005). The adsorption of organic functional groups to iron oxides or different metallic oxide can (i) facilitate anion adsorption by cation bridges $\left(\mathrm{Al}^{3+}\right.$ and $\mathrm{Fe}^{3+}$ ), (ii) amplify Specific Surface Area (SSA) by impeding mineral crystallization of $\mathrm{Fe}^{3+}$ and $\mathrm{Al}^{3+}$, (iii) change surface charges, (iv) raise up competition with different anions for adsorption sites and (v) enhance desorption of adsorbed phosphorus (Guppy et al., 2005; Fink et al., 2016).

Vital for the phosphorus availability increase via integrated compost are the composition and the environmental stipulations (Bernal et al., 2009). Hence, the phosphorus content in compost is dependent on the original source material; however, this can be enhanced via co-composting of rock phosphate. Again, a direct use of rock phosphate in mixture with compost will increase the solubility of rock phosphate (Zaharah et al., 1997; Akande et al., 2005). To reach an optimal and efficient furnish of phosphorus to the crop, compost can be mixed with inorganic fertilizer (Verma, 2013). Besides being a gradual launch phosphate fertilizer, compost supports phosphorus availability additionally via a number similarly properties: It is complexing aluminum and iron ions so that these cannot adsorb phosphorus anymore. Compost drives the production of microbial biomass (Iyamuremye et al., 1996; Ayaga et al., 2006; Fuentes et al., 2008; Khan et al., 2009). This build-up of microbial biomass leads to immobilization of phosphorus, as microbial biomass uptakes phosphorus to make its cell components. 
Then at some point of microbial biomass turnover, the phosphorus becomes available to plants. Furthermore, in the course of decomposition of organic substances natural anions are produced and released, which supports phosphate solubility. Additionally, compost can promote soil $\mathrm{pH}$ due to an alteration of the ion exchange capacity (Bernal et al., 2009). For a high phosphorus availability, a neutral pH degree between 6 and 7 is optimal.

Decreasing the $\mathrm{pH}$ of alkaline soils is, in accordance to Hopkins et al. (2005), for most plants that are no longer a reasonably priced option. However, the choice to amplify the $\mathrm{pH}$ of acidic soils with the use of lime is viewed as a right treatment to enlarge phosphorus availability (USDA, 2014; Antoniadis et al., 2015; von Tucher et al., 2017). This is supported by von Tucher et al. (2017), who examined a 36-years long-term subject research in Germany, where soils are commonly rich in phosphorus. They have calculated that the investigated crops: sugar beet, wheat, and barley confirmed sufficient growth at soil phosphorus stages that are lower than the presently encouraged levels in Germany if low soil $\mathrm{pH}$ was stronger by way of liming. However, if the phosphorus content of the soil is low, the utility of phosphate fertilizer might also be necessary for meeting the conditions for plant development (Antoniadis et al., 2015).

Another administration alternative to enlarge the availability of phosphorus may be the trade towards soil conservation systems, like agricultural no-till system. No-till systems commonly have shown fantastic outcomes on phosphorus availability. No-till will increase organic fractions and accumulates inorganic and natural phosphorus content in near-surface layers. Furthermore, it reduces erosion and increases soil moisture, which makes the transport of phosphorus to plant roots simpler (Schoenau et al., 2007; Pavinato et al., 2015).

\section{Phosphate Solubilization by Microbes}

The use of traditional fertilizers has regularly been verified to be inefficient. A way to overcome this hassle can be the inoculation of soils with phosphate solubilizing microorganisms, which have the ability to solubilize the insoluble types of phosphorus. Among those, organisms from the genera of Pseudomonas, Bacillus, Rhizobium, and Aspergillus can be found. They can produce certain enzymes such as phosphatases that help with the transformation of phosphorus to a soluble form (Mahdi et al., 2012). As described previously, phosphorus is existing mainly in insoluble forms and hence now not able to help plants. Microorganisms have been identified in the soil to raise out many biotic approaches which immediately or circuitously affect plants. The most studied of these organisms are these found very close to the root structure of the plants, the rhizosphere. However, a variety of them have been found to inhabit the internal part of the plants. They are called the endophyte whilst those on the exterior of the plant are the ectophyte. These organisms encompass protozoan, nematode, actinomycetes, fungi, archaea, and bacteria. Some of these organisms are observed to purpose ill-effect on plant increase as they motive illnesses and thereby reducing the total output of the plant with most impact on cash crops, and as so-called phytopathogens.

Some others have no average impact on the plant as they are free-living organisms. The last group of root-associated organisms are these that promote the upspring of flowers by numerous processes either internally or in the rhizosphere. The presences of these microbes are regulated by way of the plant in the structure of the exudate they produce. It's a well-known trust that microbes are attracted to the rhizosphere normally due to the fact of the chemical composition of the root exudate produced with the aid of the plant of which flavonoid is a fundamental component. However, root exudate also consists of antimicrobial element which resists the invasion by using some microorganisms, thereby performing as a structure of defense for the plant and a capability by which flora regulates the microbial community related with it. The beneficial microbes consist of a number species of actinomycetes, bacteria, fungi, some nematodes, and protozoans. Many of these organisms have demonstrated to be really helpful to plant via carrying one or greater things to do that decorate plant growth or rather put them in a top developing condition.

Among the beneficial microbes, bacteria and fungi are a major stakeholder and as such have been the most studied in particular in instances pertaining to plant boom promotion. Beneficial bacteria have been put together in the category of plant growth promoting rhizobacteria (PGPR). These bacteria are of superb 
advantage to flora in that they are successful in promoting plant increase and increasing yield in the case of cash plants. They are normally characterized via their ability to rapidly colonize the rhizosphere in particular those with flagellum, like in the case of Pseudomonads, able to outcompete other organisms and survive the face of opposition and ought to be capable to promote boom of plant. Plant growth enhancing rhizobacteria have a number of mechanisms via which they facilitate plant growth and it can both be circuitously or directly. Indirect boom promotion entails inhibiting the impact of deleterious organisms or getting rid of phytopathogens which would have instead prompted various diseases, whilst directly involves the production of phytohormones, and making nutrients reachable to the plant.

Such nutrient involves nitrogen, as seen in some PGPR successful of fixing it in the soil thereby making it more reachable to the plant. Another main activity is the solubilization of phosphate in the soil, making phosphate accessible to the plant. Fungi have additionally been capable to create an association with plant which is extraordinarily beneficial. Just like the bacteria, the fungi have also been classified within the group of plant growth promoting fungi (PGPF). Plant growth promoting fungi have the potential to shield the plant from deleterious organisms via producing antibiotics, opposition with pathogens for food and space, and inducing systemic resistance. They additionally promote shoot and root growth, flowering and enhancing yield. Apart from the plant growth promoting fungi there are additionally the mycorrhiza fungi which partner with root of plant to shape a mutualistic relationship. Farmers, in their effort to make bigger the quantity of nutrient availability to plant, have adopted the use of chemical fertilizer, a method which ought to expand the amount of phosphate available to plant however the tragedy is that most of this utilized phosphate thing of the fertilizer as soon as they get to the soil becomes locked up by means of interaction with compounds in the soil and hence inaccessible to the plant (Arumanayagam et al., 2014). Microorganisms have been the solely reliable fallback option for a tremendous treatment to the phosphate lockup mess and also to limit the severe effect of chemical fertilizer (Walpola et al., 2013). Quite a range of microorganisms have been recognized that solubilize unavailable phosphate in the soil. These microbes can either be bacteria, fungi or algae (Kucey, 1983) and are summarized into the category of Phosphate Solubilizing Microorganisms (PSM).

\section{The rhizosphere and myriad of microbes}

The rhizosphere is the soil located around the root and beneath, having an impact on the root. It is a web site with complex interactions between the root and associated microorganisms (Sylvia et al., 1998). The rhizosphere is a surrounding with high microbial diversity. This is brought about by means of an accelerated nutrient supply for microorganisms considering the fact that roots launch a multitude of organic compounds (e.g., exudates and mucilage) derived from photosynthesis and different plant mechanisms (Brimecombe et al., 2007).

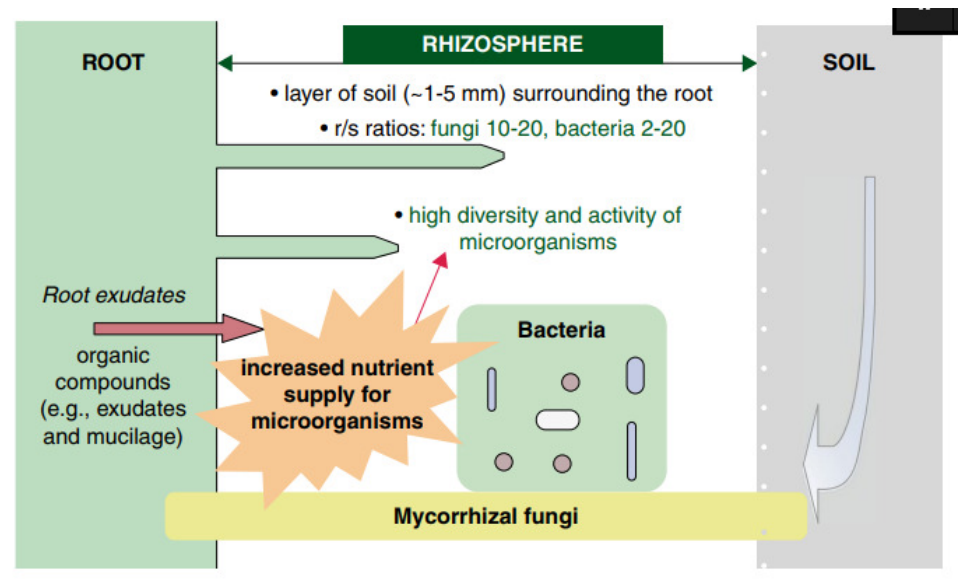

Figure 4. Rhizosphere microorganisms as a critical link between plants and soil (Adapted from Richardson et al., 2009). 
The best element of microorganisms which inhabit the rhizosphere are fungi and bacteria. When thinking about the rhizosphere effect on their abundance, the fungal abundance is 10-20 times higher and the bacterial abundance 2-20 times higher in the rhizosphere than in the bulk soil (Morgan et al., 2005). Competition for nutrient sources in the rhizosphere is very high. Therefore, several microorganisms have developed awesome strategies, giving upward push to a range of antagonistic to synergistic interactions, each amongst themselves and with the plant (Perotto et al., 1997). A very high range of interactions can be assumed on the foundation of the gorgeous diversity of soil microorganisms and plants. The understanding of the fundamentals of these interactions is vital for their use in plant growth promotion and clean-up of disturbed soils.

\section{How these plant growths promoting rhizobacteria (PGPR) help with plant survival?}

One of the procedures is with the aid of plant root association with a fungus, in any other case referred to as a mycorrhiza. The most common mutualistic association between fungi and plant roots is the mycorrhizal symbiosis. In this association, the fungal companion can provide the plant with more desirable entry to water and nutrients due to the extended region for their acquisition through the extra radical hyphal network. Additionally, many fungal companions can efficaciously make a contribution to the nutrient mobilization in the soil. They are able to produce enzymes involved in the hydrolysis of nitrogen and phosphorus compounds from the natural count number in the soil and contribute to the weathering of minerals, e.g., by using the release of natural acids. Mycorrhizal fungi can reduce abiotic (e.g., improved heavy steel concentrations) and biotic (e.g., soil-borne pathogens) stress by increasing plant fitness through superior nutrient furnish and in case of ectomycorrhizal fungi by way of masking the exceptional roots with a hyphal mantle. The plants, in return, furnish carbohydrates for fungal growth and upkeep (Smith et al., 1997). It has been estimated that between 4 and $20 \%$ of net photosynthates ought to be transferred from the plant to its fungal associate (Morgan et al., 2005).

A quantity of rhizobacteria have been related with plant growth promoting and survival mechanisms. Plant growth-promoting rhizobacteria (PGPR) are free-living soil-borne bacteria that colonize the rhizosphere, and when utilized on seed or vegetation enhance the boom of vegetation (Kloepper, 1980). In their big numbers, rhizosphere bacteria continually metabolize a number of organic compounds from root exudates. However, the range and shape of bacterial communities is plant-specific and varies over time (Smalla et al., 2001; Barriuso et al., 2005). Diversity of bacteria is affected by using the plant age, the season and the soil conditions (Hrynkiewicz et al., 2010a). Rhizosphere bacteria can have a negative, impartial or positive impact on plant fitness. Detrimental microbes consist of both most important plant pathogens and minor parasitic and non-parasitic deleterious rhizosphere microorganism (Barea et al., 2005). Plant growth promoting rhizobacteria (PGPR), can have biofertilizing and/or biocontrol functions (Barea et al., 2005). However, the effect of rhizosphere bacteria relies upon generally on the genotype of the microorganisms and flowers worried as well as on the environmental prerequisites (Brimecombe et al., 2007). Pseudomonas spp. and Bacillus spp. belong to the largest organizations of rhizosphere bacteria (Brimecombe et al., 2007).

Plant growth-promoting rhizobacteria enhance plant increase either with the aid of direct or indirect mechanisms (Glick, 1995). Plant growth promotion rhizobacteria that have been profitable in enhancing the boom of vegetation such as canola, soybean, lentil, pea, wheat, and radish have been isolated (Kloepper et al., 1988; Chanway et al., 1989; Glick et al., 1997; Timmusk et al., 1999; Salamone, 2000). Bacterial inoculants which assist in plant boom are usually viewed to be of two sorts a) symbiotic and b) free-living (Kloepper et al., 1988; Frommel et al., 1991). Beneficial free-living bacteria referred to as PGPR are observed in the rhizosphere of the roots of many specific plant life (Kloepper et al., 1989). Breakthrough research in the discipline of PGPR came about in the mid-seventies with research demonstrating the capability of Pseudomonas strains capable of controlling soil-borne pathogens to indirectly facilitate plant boom and amplify the yield of potato and radish flora (Burr et al., 1978; Kloepper et al., 1980; Kloepper et al., 1981; Howie et al., 1983). The direct increase merchandising mechanisms are as follows i) nitrogen fixation ii) solubilization of phosphorus iii) sequestering 
of iron by way of manufacturing of siderophores iv) production of phytohormones such as auxins, cytokinins, gibberellins, and v) reducing of ethylene attention (Kloepper et al., 1989; Glick, 1995; Glick et al., 1999).

For instance stress GR12-2, Pseudomonas putida, isolated from the rhizosphere of flowers growing in the Canadian High Arctic, was found to promote growth of canola cv. 'Tobin' by fixing nitrogen and improving the uptake of phosphate beneath gnotobiotic conditions (Lifshitz et al., 1986; Lifshitz et al., 1987), through synthesizing siderophores that can solubilize and sequester iron from the soil and provide it to the flowers (Glick, 1995), by production of the phytohormone IAA (Xie et al., 1996) and by way of reducing of ethylene concentration on by way of manufacturing of the enzyme ACC deaminase (Glick et al., 1994b). The oblique mechanisms of plant growth promotion with the aid of PGPR encompass (i) antibiotic production (ii) depletion of iron from the rhizosphere (iii) synthesis of antifungal metabolites (iv) manufacturing of fungal mobile wall lysing enzymes (v) opposition for web sites on roots and (vi) induced systemic resistance (Weller et al., 1986; Kloepper et al., 1988; Dunne et al., 1993; Liu et al., 1995; Glick et al., 1999).

The soil $\mathrm{pH}$ is correlated with various biological and other chemical soil properties. About $40 \%$ of cultivated soils globally have acidity issues leading to large decreases in crop production regardless of the adequate supply of mineral nutrients such as nitrogen, phosphorus and potassium (von Uexküll et al., 1995; Herrera-Estrella, 1999). In acid soils predominant constraints to plant boom are toxicities of hydrogen $(\mathrm{H})$, aluminium $(\mathrm{Al})$ and manganese $(\mathrm{Mn})$ and deficiencies of $\mathrm{P}$, calcium $(\mathrm{Ca})$ and magnesium $(\mathrm{Mg})$. Among these limitations Al toxicity is the most necessary yield-limiting component (Marschner, 1991). Availability of Phosphorus (P) to plant roots is limited each in acidic and alkaline soils, mainly, due to formation of sparingly soluble phosphate compounds with Aluminium and Iron in acidic and Calcium in alkaline soils (Marschner, 1995).

Mycorrhizal fungi vary with regard to their $\mathrm{pH}$ optima for boom and root colonization possible (Erland et al., 2002). Changes in soil $\mathrm{pH}$ can alter the enzymatic processes of some fungi in view that at least some of the enzymes produced by EM have alternatively slender pH optima (Leake et al., 1997). The colonization density of the ectomycorrhizal fungal species Cenococcum geophilum grew more on beech (Fagus sylvatica L.) with reducing soil $\mathrm{pH}$ (Kumpfer et al., 1986). Beside mycorrhizal fungi, bacteria can in truth enhance the adaptation of flora to an extreme soil $\mathrm{pH}$, though their distribution itself is controlled notably via the soil $\mathrm{pH}$ (Fierer et al., 2006). Most prokaryotes grow at tremendously narrow $\mathrm{pH}$ levels close to neutrality. A typical adaptation to severe $\mathrm{pH}$ ranges is to regulate the intracellular $\mathrm{pH}$ and maintain it close to neutral. Some enzymes determined in the bacterial outer membrane tend to have low $\mathrm{pH}$ optima, whereas all known cytoplasmic enzymes have $\mathrm{pH}$ optima ranging from $\mathrm{pH}$ 5-8 (Torsvik et al., 2002). Also, in perturbed arable and landfill soils the $\mathrm{pH}$ was a major control of the density of cultivable bacteria in the rhizosphere of willows (Salix spp.) (Hrynkiewicz et al., 2010a).

\section{Phosphate solubilizing bacteria}

Another way of growing the availability of phosphorus for vegetation is the use of phosphate solubilizing bacteria. Those microorganisms have received growing interest as bio-fertilizers in the previous few years as their use enhances soil fertility and with that, plant growth and yield. Furthermore, they are environmentally pleasant and reasonably priced (Chand and Singh, 2006; Rodríguez et al., 2006; Mahdi et al., 2012; Suleman et al., 2018). Among phosphate solubilizing bacteria, which belong to the household of plant growth promoting bacteria (PGPB), Pseudomonas and Bacillus have led to the high-quality improvement of grain yield of wheat and different crops and are therefore the most promising contributors of the group. (Rodríguez et al., 2006; Suleman et al., 2018).

Phosphate solubilization by phosphate solubilizing bacteria (PSB)

Bacteria are actively concerned in phosphorus solubilization, as such, they are referred to as Phosphate solubilizing bacteria (PSB). PSB are a part of Plant Growth Promoting Rhizobacteria (PGPR) which colonize the rhizosphere of plants, without delay or indirectly facilitating plant growth and improvement by the 
application of various mechanisms such as production of phytohormone, antibiotics, siderophores, and solubilization of phosphorus which a vital part of their activity. Not all plant growth promoting rhizobacteria are phosphate solubilizing bacteria and not all phosphate solubilizing bacteria are plant growth promoting rhizobacteria. This is because some organism which have the potential to promote the growth of plant do now not without a doubt have any relationship with the rise in the phosphate degree of the organism while some organisms which solubilize phosphate do not promote boom by using basically making phosphate available.

Plant growth promoting rhizobacteria are naturally observed in unique type of soils, specifically in that which allows for cultivation. However, due to excessive temperature and low organic content, their populace is restrained in arid and semi-arid regions. This is due to the fact their population is entirely structured on the physicochemical properties, organic matter and phosphate content material of the soil. Plant growth promoting rhizobacteria possess phosphate solubilizing potential and they can convert the insoluble compounds of phosphate into soluble types in soil and make them reachable to plants. In the presence of carbon source, bacteria accumulate phosphorus by swiftly immobilizing it even in low phosphate soils. Subsequently, phosphate solubilizing bacteria end up as a wellspring of phosphorus to flora upon its release from their cells. Among the soil bacterial communities, Phosphate solubilizing bacteria lines from Pseudomonas and Bacilli (Ordonez et al., 2016), and endosymbiotic rhizobia have been described as the most high-quality phosphate solubilizers. Examples of such species include Bacillus megaterium, B. circulans, B. subtilis, B. polymyxa, B. sircalmous, Pseudomonas striata, and Enterobacter are the most powerful Phosphate solubilizers. Acetobacter sp., Acetobacter diazotropicus, Agrobacterium sp. and Alcaligenes sp., Corynebacterium sp., Azotobacter chroococcum, Burkholderia sp., Gluconacetobacter sp., Enterobactersp. Flavobacterium sp. and Micrococcus sp.

Phosphate solubilizing bacteria act on sparingly soluble soil phosphates, majorly through chelationmediated mechanisms. Plant growth promoting rhizobacteria commonly have mineralization and solubilization potential for natural and inorganic phosphorus respectively, which has been locked up the soil and therefore no longer biologically accessible (Khan et al., 2009). The primary phosphate solubilization mechanisms utilized through phosphate solubilizing bacteria consist of the launch of complexing or mineral dissolving compounds e.g. organic acid anions, siderophores, protons, hydroxyl ions, $\mathrm{CO}_{2}$, etc. release of extracellular enzymes and launch of phosphorus in the course of substrate deterioration. The ability of a microorganism to solubilize phosphorus is primarily based on the capability of the organism to perform any of the activities cited above. Insoluble phosphate in the soil exists in two phases, the inorganic and the natural phosphate.

\section{Solubilization of inorganic phosphate by phosphate solubilizing bacteria (PSB)}

Phosphate solubilizing bacteria (PSB) are capable to solubilize inorganic phosphate compounds which are frequently insoluble such as rock phosphate, tricalcium phosphate and iron- and aluminium-bound phosphate (Mahdi et al., 2012).

Generally, their awareness is extensively greater in the rhizoplane and rhizosphere than in the different areas of the soil (Rossolini et al., 2004). There are two routes by which phosphate solubilizing bacteria can solubilize phosphorus. First, they secrete sure organic acids that assist with dissolving unavailable phosphorus to plant-available types such as orthophosphates $\left(\mathrm{HPO}_{4}^{2-}\right.$ and $\left.\mathrm{H}_{2} \mathrm{PO}^{4}\right)$. The most time-honored acid is gluconic acid, which is produced in the direct oxidation pathway of glucose through the enzyme glucose dehydrogenase. Other acids encompass acetic, succinic and oxalic acid, whose production can lead to a decrease of the $\mathrm{pH}$ content of the soil down to 2 (Suleman et al., 2018). Several fungi, such as Aspergillus sp. and Rhizopus sp., are capable to solubilize phosphate with the assistance of acids as well (Mahdi et al., 2012). The emitted acids prefer the solubilization of phosphate in special ways. On the one hand, they dissolve tricalcium phosphate to di- and monobasic phosphates, which enhances the plant availability of phosphorus. On the other hand, the acids compete with soil phosphorus for fixation sites of insoluble Aluminium and Iron oxides. When 
acids react with aluminium and iron oxides they form chelates, which are steadier and much less reactive than their acyclic forms.

Thus, fewer reactions show up between aluminium or iron oxides and phosphate. However, unique accessory minerals such as magnesium and calcium in rock phosphates have an effect on the extent of phosphate solubilization as they may react with phosphorus when the soil $\mathrm{pH}$ increases. Moreover, free carbonates in rock phosphate decrease the solubilization of phosphate as high levels of acids need to be used for their neutralization (Mahdi et al., 2012). Inorganic phosphate solubilization by means of bacteria can both occur through the production of natural acid (Vazquez et al., 2000), lowering the $\mathrm{pH}$, or by using the chelation of cations, those of calcium, aluminum, and iron bonded to phosphorus or by way of forming their soluble compounds. The reduction in $\mathrm{pH}$ of the medium suggests the release of natural acids by using the phosphate-solubilizing microorganisms. Such organic acids can both immediately dissolve the mineral phosphate because of anion exchange of phosphate via acid anion or can chelate $\mathrm{Fe}, \mathrm{Al}$ and $\mathrm{Ca}$ ions related with $\mathrm{P}$ (Khan et al., 2009). The synthesis and discharge of natural acid by means of the phosphate-solubilizing microorganisms (PSM) gets into the surrounding environment, acidify the cells and their surrounding environs that finally lead to the launch of phosphate ions from the phosphorus mineral via $\mathrm{H}^{+}$substitution for the cation attached to phosphate. Important amongst the acids launched by using plant growth promoting rhizobacteria (PGPR) in the solubilization of phosphate are gluconic acid, oxalic acid, citric acid, lactic acid, tartaric acid, and aspartic acid (Padmavathi, 2015).

Evidence from an abiotic study applying $\mathrm{HCl}$ and gluconic acid to solubilize phosphate also indicated that chelation of $\mathrm{Al}^{3+}$ via gluconic acid may also have been an element in the solubilization of aluminium phosphate. However, it has been said that the power to solubilize phosphate is no longer entirely dependent on the potential to decrease the $\mathrm{pH}$ of the medium as some of the works completed refuses correlation between solubilization of phosphate and the $\mathrm{pH}$ of the medium. Hence, the capability to solubilize phosphate was once linked to both chelation and decrease processes. The solubilization of insoluble phosphate via inorganic acid (e.g. $\mathrm{HCl}$ ) has also been reported, although $\mathrm{HCl}$ was capable to solubilize much less Phosphorus from phosphate of calcium as in contrast to any of the organic acids such as citric acid or oxalic acid at equal $\mathrm{pH}$. The manufacturing of nitric and sulphuric acids by way of Nitrosomonas and Thiobacillus species which can also dissolve phosphate compounds. $\mathrm{H}_{2} \mathrm{~S}$ has additionally been located to react with ferric phosphate to yield ferrous sulphate with the launch of phosphate. There is another advice that phosphate solubilization process occurs as a result of microbial sulphur oxidation, nitrate production, and $\mathrm{CO}_{2}$ formation.

These processes result in the formation of inorganic acids like sulphuric acid. However, their effectiveness has been much less accepted than that of the engagement of organic acids in solubilization. $\mathrm{H}^{+}$ excretion originating from $\mathrm{NH}_{4}{ }^{+}$assimilation as proposed by using Parks et al. (1990) may be the alternative routes of phosphate solubilization. They additionally suggested that the most possibly motive for solubilization without acid production is the launch of protons accompanying respiration or $\mathrm{NH}_{4}^{+}$assimilation. $\mathrm{NH}_{4}^{+}$driven proton release appears to be the important mechanism in phosphate solubilization in some organisms. In a research about using Pseudomonas fluorescens, using glucose as an alternative of fructose had the best effect on proton release as a substitute than an alternate in the use of $\mathrm{NH}_{4}$ as a substitute of $\mathrm{NO}_{3}$. Further, the involvement of the $\mathrm{H}^{+}$pump mechanism in the solubilization of small amounts of phosphate in Penicillium rugulosum was recorded.

Acidification of the rhizosphere of cactus seedlings after inoculation with the plant growth-promoting bacterium Azospirillum brasilense, in the presence or absence of ammonium and nitrate, was studied and it used to be assumed that the effect of inoculation with this plant growth promoting bacteria (PGPB) on plant growth, combined with nitrogen nutrition, might be affecting one or more of the metabolic pathways of the plant which increases proton efflux from roots and liberation of natural acid, leading to rhizosphere acidification. This suggests that for exclusive species, specific mechanisms are accountable for proton release, solely partly depending on the presence of $\mathrm{NH}_{4}{ }^{+}$. Goldstein (1995), warned that extracellular oxidation by direct oxidation pathway can also play a paramount role in soils where calcium phosphates provide a big pool 
of unavailable mineral phosphorus. Another mechanism of microbial phosphate solubilization is the liberation of enzymes or enzymolysis, the mechanism of phosphate solubilization by phosphate-solubilizing microorganisms (PSM) in a medium containing lecithin, the place where the increase in acidity is brought about by way of enzymes that act on lecithin and produce choline. The manufacturing of siderophores, which are capable of scavenging iron from the mineral phases via forming soluble $\mathrm{Fe}^{3+}$ complexes, have also been proven to be part of the mechanism by using, which plant growth promoting rhizobacteria (PGPR) releases phosphate to the soil by way of selecting up iron from Fe-P compounds and also limiting the quantity of iron easily handy to tie down phosphorus in the soil, such iron is also quite simply accessible to the plant and much less accessible to phytopathogen.

\section{Solubilization of organic phosphate by phosphate solubilizing bacteria (PSB)}

The other mechanism of how bacteria solubilize phosphate is the production of phosphatase enzymes. For this structure of solubilization of phosphorus, additionally recognized as natural phosphate mineralization, organic remember in the soil is necessary. This natural matter consists of natural phosphorus compounds. Bacteria and different saprophytes decompose those compounds with exclusive phosphatases, additionally referred to as phosphohydrolases. The microbial mineralization technique is affected through countless environmental parameters. The $\mathrm{pH}$ is quintessential for phosphorus availability. Phosphatases are grouped in acid or alkaline, depending on the $\mathrm{pH}$ cost at which they exhibit their top of the line catalytic activity. Additionally, acidic phosphatases are further divided into particular or nonspecific acidic phosphatases. The precise phosphatases consist of nucleotidases, hexose phosphatases, and phytases. The bacteria secrete some phosphatases backyard their plasma membrane in a soluble structure and others as membrane-bound proteins. Due to that, natural phosphoesters can be detected easily (Mahdi et al., 2012). Organic phosphoesters are phase of excessive molecular weight material, for instance DNA, and are now not capable to go the cytoplasmic membrane.

Therefore, they have to be converted to low molecular weight aspects to furnish the bacterial cell with the essential nutrients. This conversion mechanism might be sequential. For example, DNA might be modified with the aid of DNAse to nucleoside monophosphate which is then damaged down by way of phosphatase to phosphate and organic by-products. The decomposing rate and therefore the mineralization of natural phosphorus relies upon on the bio- and physicochemical features of the molecules. Molecules such as nucleic acids or phospholipids are easily degraded, whereas phytic acids, or polyphosphates are fragmented more slowly (Mahdi et al., 2012).

Organic phosphate is largely in the structure of inositol phosphate (making up of about 50 percent of the complete soil natural phosphate), phytin, phosphomonoesters, phosphodiesters, phospholipids, nucleic acids, and phosphotriesters, sugar phosphates, nucleotides phosphoprotein, and two phosphonates. They all in group represent about 30 to 50 percentage of the whole soil phosphate (Sharma et al., 2013). In addition, enormous portions of phosphonates that are usually given up into the surroundings in the structure of pesticides, detergent additives, antibiotics, and flame retardants additionally include organic phosphate. They are an essential financial institution of immobilized phosphate. Most of these organic compounds are high molecular-weight materials that are generally resistant to chemical hydrolysis and must, therefore, be biotransformed to either soluble ionic phosphate $\left(\mathrm{Pi}, \mathrm{HPO}_{4}^{2-}, \mathrm{H}_{2} \mathrm{PO}_{4}^{-}\right)$, or low molecular-weight organic phosphate, that can be assimilated by way of the mobile (Sharma et al., 2013).

Phosphorus mineralization refers to the solubilization of organic phosphorus and the deterioration of the remaining portion of the molecule. Sink theory is one of the most vital approach of solubilization of organic phosphate and it refers to continuous removal of phosphate that results in the dissolution of Ca-P compounds. Ultimately, the decomposition of phosphorus in organic substrates is consistently correlated with the phosphate content in the biomass of phosphate-solubilizing microorganisms (PSM). Different groups of enzymes are involved in this. The first groups of enzymes are those that dephosphorylate the phosphor-ester or phosphoanhydride bond of organic compounds. They are non-specific acid phosphatases (NSAPs). The 
frequently studied among these NSAPs enzymes released by PSM are the phosphatases. These enzymes can either be acid or alkaline phosphomonoesterases. The $\mathrm{pH}$ of most soils where phosphate activities were reported ranges from acidic to neutral values. This implies that acid phosphatase plays a major role in this process. Another enzyme manufactured by phosphate-solubilizing microorganisms (PSM) in the process of organic phosphate mineralization is phytase. This enzyme helps to produce phosphorus from organic materials such as plant remains in the soil that is stored in the form of phytate. Phytate degradation by phytase releases phosphorus in a form that is available for plant use. Plants generally cannot acquire phosphorus directly from phytate, however, the presence of phosphate-solubilizing microorganisms (PSM) within the rhizosphere may make up for a plant's inability to otherwise acquire phosphorus directly from phytate.

\section{Solubilization of phosphate by phosphate solubilizing fungi (PSF)}

Several fungi species have been isolated and known to naturally solubilize insoluble phosphorous in the soil. Among them are species of Aspergillus and Penicillium which are the most studied and effective fungi capable of solubilization of phosphate (Lima-Rivera, 2016). several other fungal species are also known to solubilize distinct form of phosphate such as rock phosphate, aluminum phosphate, and tricalcium phosphate. Such fungi include Aspergillus niger, Aspergillus tubingensis, Aspergillus fumigatus, Aspergillus terreus, Aspergillus awamor, Penicillium italicum, Penicillium radicum, Penicillium rugulosum, Fusarium oxysporum, Curvularia lunata, Humicola sp., Sclerotium rolfsii, Pythium sp., Aerothecium sp., Phoma sp., Cladosporium sp, Rhizoctonia sp., Rhizoctonia solani, Cunninghamella spp., Rhodotorula sp., Candida sp., Schwanniomyces occidentalis, Oideodendron sp., Pseudonymnoascus sp., others include Candida tropicalis, Geotrichum candidum, Geotrichum capitatum, Rhodotorula minuta and Rhodotorula rubra (Gizaw et al., 2017).

Other kinds of fungi such as those that form a mycorrhizal relationship with plant have also been known to be essential in the solubilization of phosphate. There are two types of mycorrhizal fungus, the endomycorrhiza or vascular arbuscular mycorrhizal (VAM) and the ectomycorrhizal. Ectomycorrhizal associations are formed primarily by the basidiomycete's types of fungi and some by ascomycetes. The hyphae of these fungi are launched in the soil and extends over lengthy distances commonly a long way beyond the rhizosphere where the flowers struggle to access nutrient into a region in all likelihood prosperous in nutrients. They absorb minerals like nitrogen, phosphorus, potassium, calcium, sulphur, zinc, copper and strontium from this region and translocate them to the host plant. In turn, the host plant makes a provision of energy-rich components which they produce via photosynthesis to the fungus critical for its growth (Arumanayagam et al., 2014).

Effective arbuscular mycorrhizal (AM) associations may additionally assist to enhance early-season phosphate diet in crops. The external hyphae of arbuscular mycorrhizae lengthen from the root floor to the soil beyond the phosphate depletion area and so get entry to a larger volume of un-depleted soil than the root alone (Hayman, 1983; Jakobsen, 1986; Plenchette, 1988). Some hyphae may prolong greater than $10 \mathrm{~cm}$ from root surfaces (Jakobsen et al. 1992) which is a hundred times similarly than most root hairs. Also, the small diameter of hyphae $(20-50 \mu \mathrm{m})$ allow access to soil pores that cannot be explored through roots. Therefore, a root system that has fashioned a mycorrhizal network will have a greater high-quality floor region to absorb vitamins and discover a larger extent of soil than non-mycorrhizal roots. In one study, the volume was calculated to be at least a hundred times larger with mycorrhizal affiliation than in its absence (Sieverding, 1991). Moreover, mycorrhizal colonization can also induce the formation of lateral roots or make bigger root branching (Citernesi et al., 1998; Schellenbaum et al., 1991) similarly growing the extent of soil explored. Mycorrhizae also have biochemical and physiological traits which fluctuate from those of roots which can fortify phosphate availability. They can acidify the rhizosphere through expanded proton efflux or $\mathrm{pCO} 2$ enhancement (Rigou, 1994), which can mobilize phosphate (Bago, 1997), especially in neutral or calcareous soils. In acidic soils, where phosphorus is usually present with iron $(\mathrm{Fe})$ or aluminium $(\mathrm{Al})$, excretion of chelating sellers (citric acid and siderophores) by using mycorrhizae can empower bioavailable phosphate provision of the soil (Cress et al., 1986; Haselwandter, 1995). Moreover, mycorrhizae also produce phosphatases, which can mobilize P from 
organic sources (Tarafdar et al., 1994a, b). These researches suggest that mycorrhizae can access, through a number of methods, pools of soil phosphorous that are not accessible to non-mycorrhizal plants.

A primary obstacle to exploiting mycorrhizal affiliation in agricultural systems is that mycorrhizal association tends to decline as phosphorus awareness in the plant increases (Menge et al., 1978; Lu et al., 1994; Valentine et al., 2001). Higher tissue phosphorus in the plant reduces the manufacturing of spores (De Miranda and Harris, 1994) and of secondary exterior hyphae (Bruce et al., 1994). Exudation from host plant roots of signal molecules that inspire hyphal branching is improved by using phosphorus predicament in host roots (Nagahashi et al., 1996; Nagahashi et al., 2000). Therefore, growing phosphorus status of the root might also minimize the secretion of these signal molecules, thus lowering hyphal branching and mycorrhizal association.

Another property of the mycorrhiza fungi is the ability to relate with positive strains of bacterium to aid their ability to structure ectomycorrhizal symbioses (Ordonez et al., 2016). These bacterial traces are known as mycorrhizal helper bacteria (MHB). Basidiomycete among others, positively associate with mycorrhizal helper bacteria. Others, as in some ascomycete fungi like Tuber melanosporum related with soil pseudomonads. The mycorrhizal helper bacteria strains that have been known are normally of the gram-negative and gram-positive companies of bacteria such as Pseudomonas, Bacillus, Rhizobium, Burkholderia, Achromobacter, Agrobacterium, Microccocus, Aereobacter, Flavobacterium, and Erwinia. Fungi and mycorrhizal helper bacteria empower the availability of nutrients such as nitrogen, phosphorus and micronutrients by way of nitrogen fixation, phosphate solubilization or in the suppression of pathogens. Processes by which many soil fungi solubilize inorganic phosphate into the form which vegetation can access it are through the process of acidification, chelation, exchange reactions and manufacturing of natural acids (Padmavathi, 2015). Several studies have determined out that solubilization is due to chelation of Calcium ions via natural hydroxyl acids, especially lactic, glycolic, citric, succinnic and 2-ketogluconic acids (Gizaw et al., 2017). These acids are produced as stop merchandise of natural substrates and may also be more in rhizospheres due to the release of root exudates rich in organics. Fungi in the soil are capable to tour over lengthy distances easily than the PGPR, this is a plus and might also be important to the total phosphate solubilization. The lack of relationship between $\mathrm{pH}$ drop and phosphate solubilized may additionally be due to the liming impact of the rock phosphate, and the production of other metabolites by the microbes. Only the bacterial crew confirmed a tendency to lose Phosphate Solubilization potential on sub-culturing while fungi can continue their potential for over eight subculturing transfers and have been saved actively solubilizing for over 2 years. All these have been put collectively and some authors declare fungi extra fine than bacteria in the phosphorylation of phosphate (Kucey, 1983). Phosphate solubilization impact is more often than not through the response between natural acids excreted from organic matters with phosphate binders such as aluminium, iron, and calcium, or magnesium to shape stable organic chelates to free the bound phosphate ion. Acid phosphatases play a most important role in the mineralization of organic phosphorus in soil.

\section{Phosphate solubilizing microbes as biofertilizer}

Biofertilizers are made up of organisms capable of enriching the soil nutrient quality. Biofertilizers are more often than not composed of bacteria, fungi, and the blue-green algae. Biofertilizers came to be, lengthy after the introduction of chemical fertilizers. The right part was blindfolding but in a brief while, it came to reality about the disadvantage of chemical fertilizers such as leaching out, polluting water basins, making the crop more inclined to the assault of diseases, decreasing the soil fertility and for this reason inflicting irreparable injury to the ecosystem. The principle at the back of the biofertilizer strategy is that microbes have various capabilities which could be exploited for better farming practices. Replete of techniques have been adopted by using distinct microbes in the facilitating plant growth, some of which are as explained below.

\section{Production of phytohormone}

Plant growth promoting microbes often manufacture phytochemicals which help the growth of plants. They play a key role in various processes such as plant cell enlargement, cell division, flower and fruit formation, 
stem elongation. The phytohormone produced include auxins, gibberellins, cytokinins, ethylene and abscisic acid. Pseudomonas, Bacillus, Azotobacter and Azospirillum for bacteria while Fusarium moniliforme, Gibberella fujikuroi and Azospirillum lipoferum which produced gibberellins for plant growth promotion for fungi, Azotobacter chroococcum, Azotobacter beijerinckii, Pseudomonas fluorescens and P. putida synthesizes cytokinin, Colletotrichum gloeosporioides and Fusarium spp. (Fungi) while Pseudomonas, Bacillus spp. (bacteria) synthesize auxins. Several other microbes also produce one or more of these phytohormones.

\section{Production of siderophores}

These are components which are capable of utilizing the iron content of the soil and making them handy to the plant. The iron is required for a number of things with regards to function in the plant such as in photosynthesis, respiration, etc. The same iron is also needed by microbe with pathogens addition, for a number of routes of their metabolism. The manufacturing of siderophore makes the amount of iron on hand to pathogens limited, consequently their exit. Aspergillus fumigatus, Neurospora crassa, Cenococcum geophilum, and Hebeloma crustuliniforme are examples of siderophore producing fungi whilst Azotobacter and Pseudomonas spp. are important micro bacteria siderophore producer.

\section{Antibiotics production}

These are biochemical substances produced by means of plant growth promoting microorganism to put off or as an alternative limit the things to do of other microbes, specially the pathogenic microbes. Various species of bacteria and fungi are acknowledged to produce one-of-a-kind sorts of antibiotics. Of the bacteria, Pseudomonasspp, Bacillus spp amongst others are most essential with an array of antibiotics such as phenazine1-carboxylic acid (PCA), phenazine-1-carboxamide (PCN), pyoluteorin (Plt), pyrrolnitrin (Prn), 2,4diacetylphloroglucinol (DAPG), oomycin A, viscosinamide, butyrolactones, kanosamine, zwittermicin A, aerugine, rhamnolipids, cepaciamide $\mathrm{A}$, ecomycins, pseudomonic acid, and azomycin for Pseudomonads and subtilin, subtilosin A, TasA and sublancin, bacilysin, chlorotetain, mycobacillin, rhizocticins, bacillaene, difficidin and lipopeptides belonging to the surfactin, and many others by using Bacillus spp.

Among the fungi, Trichoderma spp. are acknowledged to produce Gliovirin, gliotoxin, viridin, pyrones and peptaibols which are high-quality over an array of plant pathogens. Other techniques of sickness resistance include inducing systemic resistance towards pest and pathogens, competition for nutrient thereby reducing its availability to pathogens, and manufacturing of lytic enzymes to degrade the cellphone wall of some pathogenic fungi. They are extraordinarily profitable in enriching the soil with the aid of producing natural vitamins for the soil. To convert insoluble phosphates to a form handy to the plants, like orthophosphate, is an important trait for a plant growth promoting bacteria for increasing plant yields. Some of them are already used as business biofertilizers to aid agricultural improvements. The use of biofertilizer has several benefits over chemical fertilizers, due to the fact they are considered safer than many of the chemical compounds presently in use; they do not heap up in the food chain in any form; the target organisms rarely develop resistance as is the case when chemical agents are used; and bio-fertilizing agents are not regarded damaging to ecological activities or the environment. With the goal of making the application of microbes regarded and used, Commercial biofertilizers claiming to carry out phosphate solubilization by harnessing combined bacterial cultures have been developed.

\section{Factors affecting solubilization}

Several elements have been known to have an effect on the capacity to solubilize phosphate in the soil. Important amongst the elements is the $\mathrm{pH}$ of the surroundings in which solubilization is to occur. A confirmation to this is that acidification has been the finest stated mode of phosphate solubilization usually with the aid of the production of organic acids as observed in P. aeruginosa and B. subtilis which showed maximum phosphate solubilization at $\mathrm{pH} 3$ at $28^{\circ} \mathrm{C}$. However, there is no considerable relationship between 
the quantity of phosphate solubilization and drop in $\mathrm{pH}$. This was once noticed when urea was used as a nitrogen source, the $\mathrm{pH}$ lowered from 7.0 to 5.23 .

Another factor is the temperature of the medium. However, exclusive bacteria respond differently to changing temperature ranges. Thermophiles have the ability to function even in high temperature as properly as psychrophiles at extremely low temperatures, with the aid of producing exceptional proteins which assist in decreasing the impact of the temperature stress. At low temperature, the biological activity stays low which, however, improves further with a growing temperature in the direction of optimal range, beyond which microorganisms are both desiccated or show variable responses. Most of the phosphate solubilizing plant growth promoting rhizobacteria identified are mesophile, which means they could solely be utilized under mesophilic environment. Nonetheless, thermophile and psychrophile do exist. In this regard, bacterial cultures in particular B. subtilis and B. circulans confirmed regular phosphate solubilization even at $45^{\circ} \mathrm{C}$. whilst $P$. corrugata solubilized both at psychrophilic and mesophilic temperature stages with the most solubilization at $21^{\circ} \mathrm{C}$ may want to additionally solubilize at $4{ }^{\circ} \mathrm{C}$ and at $28^{\circ} \mathrm{C}$.

Other elements encompass salt concentration, carbon, and nitrogen supply and other necessities of the particular kind of organism involved. Carbon source and nitrogen supply are essential factors that affect the solubilization of phosphate (Arumanayagam et al., 2014). Bacteria and fungi strains exhibit exclusive levels of phosphate solubilization activity, mainly when applying a variety of carbon sources such cellulose, cellobiose, carboxyl methyl cellulose, lactose, maltose, and fructose. Among the carbon sources, glucose, cellobiose, fructose, lactose is capable to decrease the $\mathrm{pH}$ of the medium to the maximum extent and results in the very best solubilization of phosphate, observed via maltose, cellulose, carboxyl methyl cellulose, and starch. $A$. aculeatus and Aspergillus sp., have been pronounced to show maximum phosphate solubilizing recreation in the presence of glucose. Most bacterial isolates also solubilized phosphorus higher in presence of glucose than other source of carbon, whilst other researchers have confirmed various ranges of utilization and solubilization in presence of a vast range of carbon sources.

It is acknowledged that nitrogen sources such as ammonium nitrogen or nitrate nitrogen significantly influenced phosphate solubilization via ectomycorrhizal fungi. It was observed that $\left(\mathrm{NH}_{4}\right)_{2} \mathrm{SO}_{4}$ was once used successfully in lowering the $\mathrm{pH}$ of the medium to 4.2 while showing additionally maximum solubilization of phosphorus. Here also the control flask revealed a drop in $\mathrm{pH}$ and phosphate solubilization due to the presence of yeast extract and glucose. When in contrast to $\left(\mathrm{NH}_{4}\right)_{2} \mathrm{SO}_{4}$ the last nitrogen sources showed a solely moderate enlarge in phosphate solubilization. This finding was once additionally proven via the outcomes of exclusive media on phosphate solubilization. L. fraterna and mycorrhizal helper bacterial (MHB) strains additionally used $\left(\mathrm{NH}_{4}\right)_{2} \mathrm{SO}_{4}$ as nitrogen supply confirmed most phosphate solubilization. Low degrees of phosphate solubilization have been discovered when $\mathrm{NH}_{4} \mathrm{NO}_{3}$ serves as the nitrogen source. Phosphorus solubilizing bacteria have also been used to affirm that phosphate solubilization relies upon the presence of ammonium as the nitrogen source. It has also been stated that in the presence of ammonium nitrogen, calcium phytate and calcium phosphate were without difficulty solubilized, due to acidification. Nitrogen sources such as ammonium nitrogen or nitrate nitrogen appreciably influenced phosphate solubilization which uses one-of-akind mechanisms to generate acidity in the culture.

\section{Dynamics of Phosphorus Adsorption from Soil by Plants}

Phosphorus elements manages the powers or properties of phosphorus which invigorate development, improvement, or changes inside a plant framework or procedure. With climb in horticultural generation and event in worldwide creation arriving at its top in the following decades, phosphorus $(\mathrm{P})$ is getting more consideration as a non-inexhaustible asset (Cordell et al., 2009; Gilbert, 2009). One impossible to miss highlight of phosphorus is its low accessibility because of moderate dissemination and high fixation in soils, which implies phosphorus can be a significant constraining element for plant development. Supporting a powerful phosphorus-providing level at the root zone can boost the effectiveness of plant roots to activate and acquire phosphorus from the rhizosphere by a coordination of root morphological and physiological versatile 
methodologies. Moreover, phosphorus take-up and use by plants has a key influence in the assurance of conclusive harvest yield. A complete comprehension of phosphorus elements from soil to plant is basic for advancing phosphorus the executives and improving phosphorus-use proficiency, focusing at diminishing compound phosphate compost use, amplifying utilization of the organic capability of root/rhizosphere forms for proficient preparation, and securing of soil phosphorus by plants. Exhaustively, in general phosphorus elements in the soil plant framework is an element of the integrative impacts of phosphorus change, accessibility, and usage brought about by soil, rhizosphere, and plant forms. This review focuses on phosphorus mobilization, take-up, and usage by plants just as the co-operations among phosphorus and different metals in the soil, for example, nitrogen $(\mathrm{N})$, magnesium $(\mathrm{Mg})$, potassium $(\mathrm{K})$, iron $(\mathrm{Fe})$, aluminum $(\mathrm{Al})$, and zinc $(\mathrm{Zn})$.

\section{Soil phosphate transformation}

Inorganic phosphorus ( $\mathrm{Pi}$ ) for the most part represents $35 \%$ to $70 \%$ of all out $\mathrm{P}$ in soil (Harrison, 1987). Essential phosphorus minerals including apatites, strengite, and variscite are entirely steady, and the arrival of accessible Phosphorus from these minerals by weathering is commonly too delayed to even think about meeting the yield request, however direct use of phosphate rocks (for example apatites) has demonstrated generally proficient for crop development in acidic soils. Be that as it may, secondary phosphate minerals including calcium $(\mathrm{Ca})$, iron $(\mathrm{Fe})$, and aluminum $(\mathrm{Al})$ phosphates fluctuate in their disintegration rates, contingent upon size of mineral particles and soil pH (Pierzynski et al., 2005; Oelkers et al., 2008). With expanding soil pH, dissolvability of $\mathrm{Fe}$ and $\mathrm{Al}$ phosphates increments however solubility of $\mathrm{Ca}$ phosphate diminishes, aside from $\mathrm{pH}$ value above 8 (Hinsinger, 2001). The phosphorus adsorbed on different soils and aluminium/iron oxides can be discharged by desorption responses. All these phosphorus structures exist in complex equilibria with one another, speaking to from entirely steady, sparingly accessible, to plant-accessible phosphorus pools, for example, labile phosphorus and solution phosphorus.

In acidic soils, phosphorus be dominantly adsorbed by aluminium/iron oxides and hydroxides, such as gibbsite, hematite, and goethite (Parfitt, 1989). Phosphorus can be first adsorbed on the surface of clay minerals and iron/aluminium oxides by forming various complexes. The non-protonated and protonated bidentate surface complexes may coexist at $\mathrm{pH} 4$ to 9 , while protonated bidentate inner-sphere complex is predominant under acidic soil conditions (Luengo et al., 2006; Arai et al., 2007). Clay minerals and iron/aluminium oxides have large specific surface areas, which provide large number of adsorption sites. The adsorption of soil phosphorus be enhanced with increasing ionic strength. With further reactions, phosphorus may be closed up in nanopores that usually occur in iron/aluminium oxides, and thereby become unavailable to plants (Arai $e t$ al., 2007).

In neutral-to-calcareous soils, phosphorus retention is overpowered by precipitation reactions (Lindsay et al., 1989), although phosphorus can also be imbibed on the surface of calcium carbonate (Larsen, 1967) and clay minerals (Devau et al., 2010). Phosphate can precipitate with calcium, producing dicalcium phosphate (DCP) that is assessable to plants. Ultimately, dicalcium phosphate can be converted into more stable forms such as octocalcium phosphate and hydroxyapatite (HAP), which are less assessable to plants at alkaline $\mathrm{pH}$ (Arai et al., 2007). Hydroxyapatite is responsible for more than $50 \%$ of overall inorganic phosphate (Pi) in calcareous soils from long-term fertilizer experiments. Hydroxyapatite dissolution increases with reduction of soil pH (Wang et al., 2008), suggesting that rhizosphere acidification may be an efficient method to mobilize soil phosphorus from calcareous soil.

Organic phosphorus (Po) contribute to $30 \%$ to $65 \%$ of the total phosphorus in soils

(Harrison, 1987). Soil organic phosphorus majorly exists in stabilized forms as inositol phosphates and phosphonates, and active forms as orthophosphate diesters, labile orthophosphate monoesters, and organic polyphosphates (Turner et al., 2002; Condron et al., 2005). The organic phosphorus can be given out through mineralization processes mediated by soil organisms and plant roots in relationship with phosphatase secretion. These processes are greatly affected by soil moisture, temperature, surface physical chemical characteristics, and soil $\mathrm{pH}$ and $\mathrm{Eh}$ (for redox potential). Organic phosphorus transformation has a enormous effect on the overall 
bioavailability of phosphorus in soil (Turner et al., 2007). Hence, the assess-ability of soil phosphorus is extremely complex and needs to be systemically evaluated because it is greatly linked with phosphorus dynamics and transformation among various phosphorus pools.

\section{Phosphorus dynamics in the rhizosphere}

The rhizosphere is the primary region of interactions among plants, soils, and microorganisms. Plant roots can enormously enhance the rhizosphere environment through their various physiological activities, especially through the exudation of organic compounds such as mucilage, organic acids, phosphatases, and some specific signalling substances, which are vital drivers of various rhizosphere activities. The chemical and biological events in the rhizosphere not only determine mobilization and acquisition of soil nutrients as well as microbial dynamics, but also modulate nutrient use efficiency of crops, and thus greatly affect crop productivity (Hinsinger et al., 2009; Richardson et al., 2009; Wissuwa et al., 2009; Zhang et al., 2010).

Due to its low solubility and mobility in soil, phosphorus can be quickly licked up in the rhizosphere by root uptake, amounting in a gradient of phosphorus concentration in a radial direction away from the root surface. In spite of total soil phosphorus content usually surpassing the plant requirements, the low mobility of soil phosphorus can mitigate its availability to plants. Soluble phosphorus in the rhizosphere soil solution should be replaced 20 to 50 times per day by phosphorus delivery from bulk soil to the rhizosphere to meet plant need (Marschner, 1995). Therefore, phosphorus dynamics in the rhizosphere are mainly controlled by plant root growth and function, and also highly related to physical and chemical characteristics of soil (Neumann et al., 2002). Because of the peculiar features of phosphorus in soil such as low solubility, low mobility, and high fixation by the soil matrix, the availability of phosphorus to plants is primarily controlled by two key mechanisms: first, spatial availability and acquisition of phosphorus in terms of plant root architecture as well as mycorrhizal association, and second, bioavailability and acquisition of phosphorus based on the rhizosphere chemical and biological processes.

\section{Spatial availability and acquisition of soil phosphorus}

$\underline{\text { Root architecture }}$

Plants are able to respond to phosphorus starvation by altering their root architecture, including root morphology, topology, and distribution patterns. Increases in root/shoot ratio, root branching, root elongation, root topsoil foraging, and root hairs are commonly observed in Phosphorus-deficient plants, while the production of specialized roots such as cluster roots occurs in a limited number of species (Lynch et al., 2008; Vance, 2008). Phosphorus deficiency has been shown to limit growth of primary roots and facilitate length and density of root hairs and lateral roots in many plant species (Lo'pezBucio et al., 2003: Desnos, 2008). The phosphorus-efficient genotypes of common bean (Phaseolus vulgaris) have more shallow roots in the topsoil where there are relatively great contents of phosphorus resources (Lynch et al., 2008). Therefore, root architecture plays a paramount role in maximizing phosphorus acquisition because root systems with higher surface area are able to explore a given amount of soil more effectively (Lynch, 1995).

Some adaptive modifications in root architecture in response to phosphorus deficiency are well documented in Arabidopsis (Arabidopsis thaliana) and in those species forming cluster roots (Lambers et al., 2006; Osmont et al., 2007; Desnos, 2008; Vance, 2008; Rouached et al., 2010). Adaptive modifications of root growth and architecture under phosphorus starvation are linked to changed carbohydrate distribution between roots and shoots, and these alterations may be caused by plant hormones (Neumann et al., 2002; Nacry et al., 2005), sugar signalling (Karthikeyan et al., 2007; Vance, 2010), and nitric oxide in the case of cluster-root production in white lupin (Wang et al., 2010). Root proliferation is aroused when plant roots encounter nutrient-rich patches, particularly when the patches are rich in phosphorus and/or nitrogen (Drew, 1975; Hodge, 2004). The root proliferation in phosphorus-rich topsoil layers is linked to a reduced root gravitropic response under phosphorus limitation (Bonser et al., 1996), and ethylene may be involved in the control of these responses (Lynch et al., 2008). Root proliferation can be greatly influenced by the phosphorus-enriched 
soil patches. However, the processes of phosphorus-dependent changes in root proliferation in response to local phosphorus supply are not fully comprehended. Localized application of phosphates plus ammonium significantly aid phosphorus uptake and crop growth through stimulating root proliferation and rhizosphere acidification in a calcareous soil (Jing et al., 2010).

\section{Bioavailability and acquisition of soil phosphorus}

Root-induced chemical and biological alterations in the rhizosphere play an essential role in facilitating the bioavailability of soil phosphorus (in surface charges on clays and Aluminium/Iron oxides are not fully understood despite some progress on the physiological control of carboxylate synthesis and excretion. Involvement of anion channels in organic acid excretion is confirmed by the action of anion channel blockers (Neumann et al., 1999; Wang et al., 2007). It is found that the Al-activated malate transporter mediates malate exudation (Hoekenga et al., 2006) and the multidrug and toxic compound extrusion transporter mediates citrate exudation (Magalhaes et al., 2007), and both may confer Al resistance. The molecular physiological mechanisms, which underlay the survival and resistance to both phosphorus deficiency and aluminium toxicity shown by some plants such as white lupin (Wang et al., 2007), warrant further investigation.

Plants can secrete phosphatase to mobilize organic phosphorus ( $\mathrm{Po}$ ) through enzyme-catalysed hydrolysis. The activities of phosphatases are up-regulated under phosphorus deficiency (Vance et al., 2003; Vance, 2008). However, the efficacy of these phosphohydrolases can be greatly altered by the availability of substrate, interactions with soil microorganisms, and soil $\mathrm{pH}$, depending on soil physical and chemical environments (George et al., 2005a). Hence, there is often no observable concord between the phosphatase activity and plant growth performance in acidic or calcareous soils. Moreover, carboxylate exudation may have strong interactions with soil, resulting in a low efficiency in phosphorus mobilization. Therefore, root-induced bioavailability and acquisition of phosphorus in alliance with root exudation should be systemically examined in the soil/rhizosphere-plant continuum. Some soil and rhizosphere microorganisms except mycorrhizal fungi (for example, plant growth promoting rhizobacteria, particularly phosphorus-solubilizing bacteria [PSB] and phosphorus-solubilizing fungi [PSF] can also aid plant phosphorus acquisition by directly increasing solubilization of phosphorus to plants, or by indirect hormone-induced stimulation of plant growth (Richardson et al., 2009). Phosphorus-solubilizing microorganisms (PSM; PSB plus PSF) account for approximately $1 \%$ to $50 \%$ in phosphorus solubilization potential (Chen et al., 2006). The PSB or PSF may mobilize soil phosphorus by the acidification of soil, the generation of enzymes (such as phosphatases and phytases), or the production of carboxylates such as gluconate, citrate, and oxalate (Jones et al., 2011).

\section{Phosphorus cycling and bioavailability in soil-plant systems}

The main pools of $\mathrm{P}$ on earth are the oceans and the lithosphere, with $<1 \%$ is found in the terrestrial ecosystems' compartments: atmosphere, plant biomass and soil (Stewart et al., 2005). Most of the phosphorus in terrestrial ecosystems is present in soils, which generally contain between 100-3000 kg ha ${ }^{-1}$, but only a little proportion of this $(<1 \%)$ is assessable to plants at any time (Condron et al., 2005; Richardson et al., 2005; Bünemann et al., 2007). The primary source of $\mathrm{P}$ in soils is the sparingly soluble calcium phosphate apatite (Newman, 1995; Walker et al., 1976). 'Labile phosphorus' refers to the soil phosphorus that is in equilibrium within the soil solution (plant available), while $\mathrm{P}$ forms that have slower equilibrium are termed 'non-labile' (Pierzynski et al., 2005). Phosphorus cycling or dynamics in soil can be defined as a sequence of processes affected by the nature of the inorganic and organic solid phases present, the type and intensity of biological process, the chemistry of the soil solution ( $\mathrm{pH}$, ionic strength, redox potential), and abiotic factors like texture and moisture content, (Bünemann et al., 2007; Pierzynski et al., 2005; Quiquampoix et al., 2005).

In general terms, the phosphorus cycle in the soil begins when primary apatite phosphate in rock breaks down due to physical and chemical weathering releasing phosphorus. Once in solution, the phosphorus incorporated into the system is converted to secondary inorganic phosphate and organic phosphorus forms, some of which are of limited availability to plants and microbial communities (Walker et al., 1976). These 
forms can be affected by chemical and biochemical activities including sorption-desorption (oxidationreduction) and mineralization immobilization (Condron et al., 2005; Pierzynski et al., 2005). Phosphorus bioavailability can be defined as the concentration of phosphorus in soil solution which is readily available for the plant and microbial demands. Soil solution is the main source of phosphorus for plants and microbes, and the majority of it is present as inorganic orthophosphates. However, when it is removed by plant and microbial consumption it has to be replenished from a combination of inorganic, organic and microbial pools (Condron et al., 2005; Pierzynski et al., 2005). Various studies have researched the systems which decide phosphorus bioavailability utilizing various methodologies, for example, phosphorus fractionation, enzyme activity, enzyme lability and 31P atomic attractive reverberation (NMR) spectroscopy.

From these investigations we realize that the bioavailability of soil phosphorus is influenced diversely by the land use management, the soil physical and chemical qualities, the kind of vegetation spread and the microbial networks inside it. For instance, Chen et al. (2000) estimated the soil phosphatase action in soils under a 19-year-old blended woodland stand of Pinus ponderosa and Pinus nigra, and a neighbouring unchanged field, and they found that the enzyme action was higher in the topsoil under grassland contrasted with the backwoods/woodland. They presumed that the lower phosphatase movement saw under woodland was identified with comparing lower biomass and microbial exercises in the forest soil. Essentially, Turner et al. (2005), utilized 31P NMR to evaluate scyllo-inositol hexakisphosphate in field soils to survey its potential bioavailability to developing plants, and they found that scyllo-inositol hexakisphosphates speak to an enormous and conceivably bioavailable part of natural phosphorus in temperate soils. The accessibility of inorganic phosphorus is commonly high in tender soils, and this relative wealth permits an enhancement of phosphorus in natural issue, during the dynamic phases of biological system improvement (Condron et al., 2005; Allison et al., 2007; Turner et al., 2007b). Be that as it may, as soil improvement proceeds, the accessibility of phosphorus diminishes because of a few variables including natural immobilization, draining, disintegration and the change of inorganic phosphorus into blocked structures, principally due to sorption and relationship with iron and aluminum oxides and hydroxides (Figure 2) (Condron et al., 2005; Pierzynski et al., 2005; Turner et al., 2007b).

Sposito (1986), clarified that sorption and desorption responses equilibrate with the soil solution since orthophosphates can be adsorbed to the surfaces and edges of hydrous oxides, earth minerals, and carbonates by supplanting $\mathrm{H}_{2} \mathrm{O}$ or $\mathrm{OH}^{-}$. The sorption procedure includes two stages: 1) adsorption which is the amassing of $\mathrm{P}$ on the surfaces of strong soil constituents; and 2) dispersion of phosphorus into strong constituents (Pierzynski et al., 2005; Sposito, 1986). Crop evacuation is additionally another significant course by which Phosphorus concentrations are brought down in the dirt framework (Pierzynski et al., 2005).

Simpson et al. (2012) considered the general dissolvability of soil phosphorus under differentiating contrasting systems. They found that phosphorus take-up was $51-54 \%$ higher under cut-out clipping-left treatments contrasted and cutting evacuated and no cutting treatments. This proposed natural and biochemical procedures related with improved mineralisation of natural phosphorus and turnover of phosphorus through the microbial biomass made a more noteworthy commitment to plant phosphorus takeup in the section left soils contrasted with different treatments. Every one of these components bring about an impoverishment of phosphorus in the natural issue pool and result in less amassing in soils, influencing carbon (C) and nitrogen (N) cycling (Condron et al., 2005).

In undisturbed biological systems where the labile inorganic phosphate part is little and the phosphorus cycle firmly shut, a large portion of the phosphorus accessible to plants is provided from the moderate reusing of plant residue phosphorus through microbial procedures in the soil (Richardson et al., 2005). Then again, McDowell et al. (2012) revealed results got from a long-time field preliminary in New Zealand which indicated that soil natural phosphorus amassed rapidly as an outcome of superphosphate inputs. Likewise, Condron et al. (1989a) found that the sums and types of natural phosphorus aggregated in a seriously munched watered prairie following 25 years of phosphatic compost application, in spite of the fact that the pace of gathering of natural phosphorus diminished with time because of expanded mineralization because of lime inclusion. 
As Bünemann et al. (2007) clarify, plant take-up and microbial immobilization decide phosphorus motions in the soil, in light of the fact that in any case the chemical harmony between various types of phosphorus would just be influenced by abiotic factors like dampness, temperature, air sources inputs and leaching depletion. Connections of solvent phosphorus with cations, the moderate pace of phosphorus dispersion and transformation to natural structures, have advanced numerous versatile techniques of plants to survive under phosphorus lacking conditions, some of which incorporate setting up plant-organism affiliations (mycorrhizae) and co-operations with other non-harmonious rhizosphere microorganisms. The absolute most sensational changes in plant roots are seen under inorganic phosphate lack conditions prompting contrasts in root morphology and engineering, root hair thickness and length, supplement ingestion rate and the capacity to adjust the rhizosphere by discharging natural acids, compounds and different substances (Vance et al., 2003; Raghotama, 2005; Chen et al., 2008). For instance, Chen et al. (2003) in a glasshouse try found that radiata pine (Pinus radiata) delivered more root exudates than ryegrass (Lolium perenne), which may have improved the disintegration of iron, aluminum and calcium minerals which thus expanded phosphorus mineralization. Soil microorganisms involve a significant source and sink for supplements like phosphorus, just as being the principle specialists for changing these components.

Beever et al. (1980) estimated the efficiencies of inorganic phosphate take-up from soil by microorganisms and plant establishes utilizing in-vitro analyzes and saw that microorganisms, particularly microscopic organisms, had more proficient take-up systems than plants. The soil fauna is less significant as a phosphorus pool yet advances the turnover of the microbial biomass by touching and predation (Bünemann et al., 2007). The harmony grouping of phosphorus in the soil arrangement, and the limit of the soil to keep up this focus against take-up by plant roots and microorganisms, is constrained by complex physico-substance and biochemical instruments (Chen et al., 2008).

The turnover of natural phosphorus is dictated by immobilization and mineralization forms, where immobilization is the transformation of inorganic to natural $\mathrm{P}$ and mineralization is the procedure by which inorganic phosphate is discharged from natural phosphorus in the soil (McGill et al., 1981; Condron et al., 2005). Since phosphorus in the soil arrangement is the chief wellspring of phosphorus for microbial take-up, microbial immobilization of phosphorus can be induced from a decline in phosphate in the soil arrangement and an expansion in microbial biomass phosphorus (Bünemann et al., 2007). After microbial demise, phosphorus immobilized can be re-mineralized or fused into soil natural phosphorus (Bünemann et al., 2007). With expanding time and weathering power, phosphorus loss from a framework could be critical and a more prominent interest on natural phosphorus can ease back its collection because of a diminishing commitment from inorganic phosphorus (requirements for phosphorus increments, and propose that hydrolysis of natural phosphorus would then be relied upon to build, easing back its aggregation. As indicated by Chen et al. (2008), the destiny and guideline of the phosphatase catalysts discharged by plant roots and microorganisms is perplexing, in light of the fact that they can be dependent upon adsorption, restraint, biodegradation, adjustment and humification relying upon the soil properties, and the sort of prevalent vegetation in the framework. An examination completed on the Franz Josef chronosequence in New Zealand demonstrated that the exercises of phosphomonoesterase and phosphodiesterase compounds increased with soil age, while their action was adversely connected with absolute phosphorus in soils (Allison et al., 2007).

\section{Chemistry and dynamics of soil organic phosphate}

\section{Chemistry}

Between 20 to $80 \%$ of the absolute phosphorus found in soils is comprised of a mix of natural and microbial phosphorus, demonstrating that natural phosphorus is consistently added to soil in plant, animals, and microbial deposits (Rubaek et al., 1993; Condron et al., 2005; Bünemann et al., 2007). Natural phosphorus speaks to between 30 to $60 \%$ of the all-out Phosphorus in plants and up to $90 \%$ in soil microorganisms (Rubaek et al., 1993; Condron et al., 2005; Turner et al., 2007a). Plants and microorganism's take-up inorganic phosphorus, which is bound to Carbon moieties through phosphorylation by numerous biochemical 
procedures (Condron et al., 2005). Concurring with Condron et al. (2005), natural phosphorus is characterized as phosphorus fortified with carbon (regularly through ester bonds (C-O-P)), which starts from a mix of animal, plant and microbial build-ups. Natural phosphorus mixes are ordered into orthophosphate esters, phosphonates and orthophosphate anhydrides dependent on the idea of the phosphorus bond (Condron et al., 2005). Tate (1984) clarified that the chemical decent variety of soil natural phosphorus is wide because of natural moieties. Orthophosphate esters are subdivided into monoesters and diesters relying upon the quantity of ester bunches connected to every orthophosphate particle. Orthophosphate monoesters are the most well-known type of natural $\mathrm{P}$ in most of soils and can speak to up to $100 \%$ of all out soil natural phosphorus (Condron et al., 2005). These incorporate sugar phosphates, phospho-proteins, mononucleotides and inositol phosphates, the last gathering being the transcendent type of orthophosphate monoesters found in many soils (Celi et al., 2005; Condron et al., 2005). Inositol hexakis and pentakisphosphate are the most plentiful types of inositol phosphates present in soil and are accepted to be gotten essentially from plants. These structures contain up to $60 \%$ of recognized soil natural phosphorus together with a lot littler measures of nucleotides, sugar phosphates and phosphoproteins, while a huge extent of the staying unidentified natural phosphorus which might be insoluble buildings with earth minerals and natural issue. Orthophosphate diesters are found in nucleic acids, phospholipids, teichoic acids and fragrant intensifies, all of which happen in a lot littler focuses contrasted and those of orthophosphate monoesters (Condron et al., 2005). By and by, these are viewed as the most bioavailable types of natural phosphorus and are the transcendent species found in plant and microorganism cells (Quiquampoix et al., 2005). Sorption of phosphorus onto soil minerals is solid and is increasingly clear for certain natural phosphorus mixes, similar to inositol hexakisphosphate, which incorporates six phosphate gatherings, three of which can get adsorbed onto iron and aluminum oxideshydroxides and soils and thusly diminishes its accessibility to compounds and microorganisms (Bünemann et al., 2007). Consequently, inositol phosphates are commonly viewed as stubborn contrasted and diester types of natural Phosphorus. Turner et al. (2007b) saw that the extent of inositol phosphates declined extraordinarily during the late phases of a 120,000 Franz Josef post-cold chronosequence in New Zealand. Then again, the extents of diester DNA expanded consistently all through the grouping. One clarification is that the decrease in inositol phosphates could be identified with the weathering of nebulous metal oxides to increasingly crystalline structures which raise the bioavailability of inositol phosphates, while DNA might be balanced out by fuse into natural issue structures. Condron et al. (2005) presumed that in spite of advances in the distinguishing proof of the synthetic types of natural phosphorus, a few elements make its identity troublesome, for example, the chemical unpredictability of soil natural phosphorus, the vulnerability of some natural phosphorus compounds to hydrolysis during extraction, solid sorption of natural $\mathrm{P}$ by muds and the formation of insoluble salts with metal cations.

\section{$\underline{\text { Dynamics }}$}

In both common and horticultural frameworks, the fuse of plant, animal and microbial build-ups (above-and subterranean) into soil gives the vitality expected to continue supplement cycles, just as guaranteeing that the phosphorus they contain re-enters the phosphorus cycle (Turner et al., 2007a).

\section{Phosphorus uptake utilization by plants}

Plant roots retain phosphorus as both of $\mathrm{H}_{2} \mathrm{PO}_{4}$ or $\mathrm{HPO}_{4}^{2-}$. Since the convergences of these particles in soils are in the micro-molar range, high-affinity dynamic transport frameworks are required for inorganic phosphate $(\mathrm{Pi})$ take-up against a lofty compound potential slope over the plasma film of root epidermal and cortical cells. This procedure is intervened by high-proclivity $\mathrm{Pi} / \mathrm{H}^{+}$symporters that have a place with the PHT1 gene family. Interruption of PHT1 gene articulation brings about a critical diminishing of phosphorus procurement by roots (Shin et al., 2004; Ai et al., 2009). What's more, a few individuals from this family are expressed explicitly or potentially up-directed in roots colonized by mycorrhizal growths, demonstrating their capacity in transport of inorganic phosphate $(\mathrm{Pi})$ by means of a mycorrhizal-subordinate pathway (Bucher, 
2007). The greater part of the Pi taken up by roots is stacked into the xylem and along these lines translocated into shoots.

The recognised regulators PHO1 and PHO1; H1 containing the SPX (for SYG/PHO81/XPR1) tripartite domain also contribute to inorganic phosphate $(\mathrm{Pi})$ translocation through loading inorganic phosphate ( $\mathrm{Pi}$ ) to the xylem (Hamburger et al., 2002; Stefanovic et al., 2007). Inside plant cells, phosphorus is a significant segment of nucleic acids, film lipids, and phosphorylated intermediates of energy metabolism. Along these lines, the cell inorganic phosphate $(\mathrm{Pi})$ homeostasis is basic for physiological and biochemical procedures. Under phosphorus insufficiency, plants can create versatile reactions not exclusively to encourage productive inorganic phosphate $(\mathrm{Pi})$ obtaining and translocation, yet additionally to use proficiently put away phosphorus by modifying inorganic phosphate $(\mathrm{Pi})$ reuse internally, restricting phosphorus utilization, and reallocating phosphorus from old tissues to tender ones as well as effectively developing tissues. Albeit $85 \%$ to $95 \%$ of the cell phosphorus is available in the vacuole, 31PNMR examinations uncover that the inorganic phosphate ( $\mathrm{Pi}$ ) efflux from the vacuole is deficient to make up for a fast abatement of the cytosolic inorganic phosphate ( $\mathrm{Pi}$ ) focus during P starvation (Pratt et al., 2009). On the other hand, a phosphate transporter PHT4;6 is situated in the Golgi layer, likely moving inorganic phosphate ( $\mathrm{Pi}$ ) out of the Golgi luminal space for the reusing of the inorganic phosphate ( $\mathrm{Pi}$ ) discharged from glycosylation (Cubero et al., 2009).

Another phosphate transporter PHT2;1 is available in the chloroplast, and can influence designation of inorganic phosphate $(\mathrm{Pi})$ inside the plant (Versaw et al., 2002). Discharging inorganic phosphate ( $\mathrm{Pi}$ ) from natural sources, for example, phosphomonoesters and nucleic acids, is likewise a significant advance for interior phosphorus reuse-forms. Phosphatases are expected to discharge inorganic phosphate $(\mathrm{Pi})$ from phosphomonoesters, and a double focused on purple corrosive phosphatase isozyme AtPAP26 (intracellular and emitted APase) is basic for productive acclimation of Arabidopsis to phosphorus lack (Hurley et al., 2010).

Ribonucleases are liable for phosphorus activation from RNA, and two qualities (AtRNS1 and AtRNS2) are up-managed by phosphorus starvation (Bariola et al., 1999). These phosphatase and ribonuclease genes are additionally actuated by leaf senescence, further supporting their significant job in the phosphorus remobilization process (Gepstein et al., 2003). To confine phosphorus utilization, layer lipid piece can be changed somewhat through a decline of phospholipids and an expansion of non-phosphorus lipids under phosphorus restriction (Essigmann et al., 1998). Deterioration of phospholipids into inorganic phosphate and diacylglycerol is interceded by phospholipases $\mathrm{C}$ and $\mathrm{D}$, which are fundamental for lipid turnover in plants adjusting to phosphorus lack (Li et al., 2006). Diacylglycerol is in this manner changed over into galactolipids or sulfolipids by two proteins SQD1 and SQD2 to practically fill in for phospholipids (Yu et al., 2002). Taken together, plants have built up a progression of versatile reactions to take up and use phosphorus effectively, including morphological, physiological, and biochemical reactions. For sure, many key players inside the system, for example, transcriptional factors (PHR1), microRNA (miR399), and ubiquitin E2 conjugase (PHO2), can manage PHT, PHO1, APase, and RNS qualities at various monitoring levels. What's more, the sugar-stimulation and hormonal systems are additionally associated with the Pi reaction (Hammond et al., 2008; Vance, 2010).

\section{Conclusions}

The phosphorus nutrition of plants is majorly monitored by phosphorus dynamics in the soil/rhizosphere-plant continuum. The spread and dynamics of phosphorus in soil has significant spatiotemporal differences. Root architecture that distributes more roots to the location where phosphorus resources are located plays a vital role in efficiently exploiting these phosphorus resources. Furthermore, root architecture can express functional coordination with root exudation of carboxylates, protons, and phosphatases in phosphorus mobilization and acquisition. The co-ordination of plant adaptations in root morphology and root physiology to phosphorus-limiting environments may effectively match heterogeneous phosphorus supply and 
spread in soil, amounting to increased spatial accessibility and bioavailability of soil phosphorus. The incorporation of phosphorus dynamics from soil to plant through the rhizosphere gives a full picture of available phosphorus behaviour and efficient acquisition in association with plant adaptive strategies. In the past two decades, great progress has been made in understanding soil, rhizosphere, and plant processes associated with soil phosphorus transformation, phosphorus mobilization and acquisitions. However, many aspects of overall phosphorus dynamics in the soil/rhizosphere-plant continuum are not thoroughly understood, including regulation of phosphorus acquisition and phosphorus-starvation rescue mechanisms in plants, the complex coordination of root morphology, physiological and biochemical responses under varying phosphorus availability, and plant sensing of heterogeneous phosphorus supply in soil. Given the usefulness of phosphorus to plants and its importance as a strategic resource, a better understanding of phosphorus dynamics in the soil/rhizosphere-plant continuum is necessary to lead the establishment of integrated phosphorusmanagement strategies involving manipulation of soil and rhizosphere activities, development of phosphorusefficient crops, and improving phosphorus -recycling efficiency in the future.

\section{Authors' Contributions}

Conceptualization: BI and GOA; Data curation: All authors; Formal Analysis: all authors; Investigation: BI, OFO, FR, and MS; Supervision: GOA and BI; Validation: all authors; Writing-original draft: BI, OFO, FR and MS; Writing-review and editing: all authors. All authors read and approved the final manuscript.

All authors read and approved the final manuscript.

\section{Acknowledgements}

This research received no specific grant from any funding agency in the public, commercial, or not-forprofit sectors.

\section{Conflict of Interests}

The authors declare that there are no conflicts of interest related to this article.

\section{References}

Ai P, Sun S, Zhao J, Fan X, Xin W, Guo Q, ... Miller AJ (2009). Two rice phosphate transporters, OsPht1:2 and OsPht 1:6, have different functions and kinetic properties in uptake and translocation. Plant Journal 57:798-809. https://doi:10.1111/j.1365-313X.2008.03726.x

Allison VJ, Condron LM, Peltzer DA, Richardson SJ, Turner BL (2007). Changes in enzyme activities and soil microbial community composition along carbon and nutrient gradients at the Franz Josef chronosequence, New Zealand. Soil Biology and Biochemistry 39:1770-1781. https://doi.org/10.1016/j.soilbio.2007.02.006

Arai Y, Sparks DL (2007). Phosphate reaction dynamics in soils and soil minerals: a multiscale approach. Advances in Agronomy 94:135-179. https://doi.org/10.1016/S0065-2113(06)94003-6

Arumanayagam S, Arunmani M (2014). Rock phosphate solubilization by the ectomycorrhizal fungus Laccaria fraterna and its associated mycorrhizal helper bacterial strains. African Journal of Biotechnology 13(25):2524-2530. https://doi.org/10.5897/AJB2014.13828 
Bariola PA, MacIntosh GC, Green PJ (1999). Regulation of S-like ribonuclease levels in Arabidopsis: antisense inhibition of RNS1 or RNS2 elevates anthocyanin accumulation. Plant Physiology 119:331-342. https://doi:10.1104/pp.119.1.331

Beever RE, Burns DJW (1980). Phosphorus uptake, storage and utilization by fungi. Advances in Botanical Research 8:127-219. https://europepmc.org/article/AGR/IND81109168

Benito M, Masaguer A, Moliner A, Arrigo N, Palma RM (2003). Chemical and microbiological parameters for the characterization of the stability and maturity of pruning waste compost. Biology and Fertility of Soils 8:339-342.

Bernal MP, Alburquerque JA, Moral R (2009). Composting of animal manures and chemical criteria for compost maturity assessment. A review. Bioresource Technology 100:5444-5433. https://doi:10.1016/j.biortech.2008.11.027

Bonser AM, Lynch J, Snapp S (1996). Effect of phosphorus deficiency on growth angle of basal roots in Phaseolus vulgaris. New Phytologist 132:281-288. https://doi:10.1111/j.1469-8137.1996.tb01847.x

Bucher M (2007). Functional biology of plant phosphate uptake at root and mycorrhiza interfaces. New Phytologist 173:11-26. https://doi.org/10.1111/j.1469-8137.2006.01935.x

Buddhi CW, Min-Ho Y (2013). Isolation and characterization of phosphate solubilizing bacteria and their co-inoculation efficiency on tomato plant growth and phosphorous uptake. African Journal of Microbiology Research 7(3):266275. https://doi.org/10.5897/AJMR12.2282

Bünemann E, Condron L (2007). Phosphorus and sulphur cycling in terrestrial ecosystems. In: Marschner P and Rengel Z (Eds). Nutrient cycling in terrestrial ecosystems. Springer-Verlag, New York, USA, pp 65-94. https://doi.org/10.1007/978-3-540-68027-7_3

Celi L, Barberis E (2005). Abiotic stabilization of organic phosphorus in the environment. In: Turner BL, Frossard E, Baldwin D (Eds). Organic phosphorus in the environment. CAB International, Wallingford, UK, pp 113-164. https://doi.org/10.1007/s11104-017-3391-x

Chand L, Singh H (2006). Effect of phosphate solubilizers with different p-levels on yield and nutrient uptake of mung (Vigna radiata.). Research Council Meet Report, Division of Agronomy, Oct 03-04, SKUAST-K.

Chen CR, Condron LM, Davis MR, Sherlock RR (2000). Effects of afforestation on phosphorus dynamics and biological properties in a New Zealand grassland soil. Plant and Soil 220:151-163. https://doi.org/10.1023/A:1004712401721

Chen CR, Condron LM, Davis MR, Sherlock RR (2003). Seasonal changes in soil phosphorus and associated microbial properties under adjacent grassland and forest in New Zealand. Forest Ecology and Management 177:539-557. https://doi.org/10.1016/S0378-1127(02)00450-4

Chen CR, Condron LM, Xu ZH (2008). Impacts of grassland afforestation with coniferous trees on soil phosphorus dynamics and associated microbial processes: A review. Forest Ecology and Management 255:396-409. https://doi.org/10.1016/j.foreco.2007.10.040

Chen YP, Rekha PD, Arunshen AB, Lai WA, Young CC (2006). Phosphate solubilizing bacteria from subtropical soil and their tricalcium phosphate solubilizing abilities. Applied Soil Ecology 34:33-41. https://doi.org/10.1016/j.apsoil.2005.12.002

Chianu JN, Chianu JN, Mairura F (2012). Mineral fertilizers in the farming systems of sub-Saharan Africa. A review. Agronomy for Sustainable Development 32:545-566. https://doi.org/10.1007/s13593-011-0050-0

Cole DW, Rapp M (2001). Elemental cycling in forest ecosystems. In: Reichle DE (Ed.). Dynamic properties of forest ecosystems. New York: Cambridge University Press, pp 341-403. http://www.cambridge.org/catalogue/catalogue.asp?isbn=9780521112208

Condron LM, Goh KM (1989a). Effects of long-term phosphatic fertilizer applications on amounts and forms of phosphorus in soils under irrigated pasture in New Zealand. Journal of Soil Science 40:383-395. https://doi.org/10.1111/j.1365-2389.1989.tb01282.x

Condron LM, Tiessen H (2005). Interactions of organic phosphorus in terrestrial ecosystems. In: Turner BL, Frossard E, Baldwin D (Editors). Organic phosphorus in the environment. CAB International, Wallingford, UK, pp 295-307.

Condron LM, Turner BL, Cade-Menun BJ (2005). Chemistry and dynamics of soil organic phosphorus. In: Sims JT, Sharpley AN (Eds). Phosphorus: agriculture and the environment. American Society of Agronomy, Crop Science Society of America, Soil Science Society of America, Inc., Madison, WI, pp 87-121. https://doi.org/10.2134/agronmonogr46.c4

Cordell D, Drangert JO, White S (2009). The story of phosphorus: global food security and food for thought. Global Environmental Change 19:292-305. https://doi.org/10.1016/j.gloenvcha.2008.10.009 
Cubero B, Nakagawa Y, Jiang XY, Miura KJ, Li F, Raghothama KG ... Pardo JM (2009). The phosphate transporter PHT4;6 is a determinant of salt tolerance that is localized to the Golgi apparatus of Arabidopsis. Molecular Plant 2:535-552. https://doi.org/10.1093/mp/ssp013

Daly K (2000). P desorption from Irish soils. In: Tunney H, Coulter B, Daly K, Kurz I, Coxon C, Jeffery D, Mills P, Kiely G, Morgan G (Eds.). Quantification of phosphorus (P) loss to water due to soil P desorption - R\&D Report series No. 6. EPA. Wexford: Johnstown Castle Estate, pp 87 pp. http://hdl.handle.net/11019/1415

Devau N, Le Cadre E, Hinsinger P, Ge'rard F (2010). A mechanistic model for understanding root-induced chemical changes controlling phosphorus availability. Annals of Botany 105:1183-1197. https://doi.org/10.1093/aob/mcq098

Drew MC (1975). Comparison of the effects of a localized supply of phosphate, nitrate, ammonium and potassium on the growth of the seminal root system, and the shoot, in barley. New Phytologist 75:479-490. https://doi.org/10.1111/j.1469-8137.1975.tb01409.x

Essigmann B, Gu“ler S, Narang RA, Linke D, Benning C (1998). Phosphate availability affects the thylakoid lipid composition and the expression of SQD1, a gene required for sulfolipid biosynthesis in Arabidopsis thaliana. Proceedings of National Academy of Sciences USA 95:1950-1955. https://doi.org/10.1073/pnas.95.4

George TS, Richardson AE, Simpson RJ (2005a). Behaviour of plant derived extracellular phytase upon addition to soil. Soil Biology and Biochemistry 37:977-988. https://doi.org/10.1016/j.soilbio.2004.10.016

Gepstein S, Sabehi G, Carp MJ, Hajouj T, Nesher MFO, Yariv I, ... Bassani M (2003). Large-scale identification of leaf senescence-associated genes. Plant Journal 36:629-642. https://doi.org/10.1046/j.1365-313X.2003.01908.X

Gilbert N (2009). Environment: the disappearing nutrient. Nature 461:716-718. https://doi.org/10.1038/461716a

Gyaneshwar P, Kumar G, Parekh L, Poole P (2002). Role of soil microorganisms in improving P nutrition of plants. Plant Soil Journal 245:83-93. https://doi.org/10.1023/A:1020663916259

Hamburger D, Rezzonico E, MacDonald-Comber PJ, Somerville C, Poirier Y (2002). Identification and characterization of the Arabidopsis PHO1 gene involved in phosphate loading to the xylem. Plant Cell 14:889-902. https://doi.org/10.1105/tpc.000745

Hammond JP, White PJ (2008). Sucrose transport in the phloem: integrating root responses to phosphorus starvation. Journal of Experimental Botany 59:93-109. https://doi.org/10.1093/jxb/erm221

Hao X, Cho C, Racz G, Chang C (2002). Chemical retardation of phosphate diffusion in an acid soil as affected by liming. Nutrient Cycling in Agroecosystems 64:213-224. https://doi.org/10.1023/A:1021470824083

Harrison AF (1987). Soil organic phosphorus-a review of world literature. CAB International, Wallingford, Oxon, UK, pp 257.

Hedley MJ, Stewart JWB, Chauhan BS (1982). Changes in inorganic and organic soil phosphorus fractions induced by cultivation practices and by laboratory incubations. Soil Science Society of America Journal 46:970-976. https://doi.org/10.2136/sssaj1982

Hinsinger P (2001). Bioavailability of soil inorganic P in the rhizosphere as affected by root-induced chemical changes: a review. Plant Soil 237:173-195. https://doi.org/10.1023/A:1013351617532

Hinsinger P, Bengough, AG, Vetterlein D, Young IM (2009). Rhizosphere: biophysics, biogeochemistry, and ecological relevance. Plant Soil 321:117-152. https://doi.org/10.1007/s11104-008-9885-9

Hinsinger P, Gobran GR, Gregory PJ, Wenzel WW (2005). Rhizosphere geometry and heterogeneity arising from rootmediated physical and chemical processes. New Phytologist 168:293-303. https://doi.org/10.1111/j.14698137.2005.01512.x

Hodge A (2004). The plastic plant: root responses to heterogeneous supplies of nutrients. New Phytologist 162:9-24. https://doi.org/10.1111/j.1469-8137.2004.01015.x

Hoekenga OA, Maron LG, Piñeros MA, Canc sado GMA, Shaff J, Kobayashi Y, ... Sasaki T (2006). AtALMT1, which encodes a malate transporter, is identified as one of several genes critical for aluminum tolerance in Arabidopsis. Proceedings of National Academy of Sciences USA 103:9738-9743. https://doi.org/10.1073/pnas.0602868103

Hopkins B, Ellsworth J (2003). Phosphorus nutrition in potato production. In: Robertson LD et al. (Eds.). Proceedings of the Winter Commodity Schools, pp 75-86.

Hopkins B, Ellsworth J (2005). Phosphorus availability with alkaline/calcareous Soil. Western Nutrient Management Conference 6:88-93.

Huang L-M, Jia X-X, Zhang G-L, Shao M-A (2017). Soil organic phosphorus transformation during ecosystem development: A review. Plant and Soil 417(1-2):17-42. https://doi.org/10.1007/s11104-017-3240-y 
Hurley BA, Tran HT, Marty NJ, Park J, Snedden WA, Mullen RT, Plaxton WC (2010). The dual-targeted purple acid phosphatase isozyme AtPAP26 is essential for efficient acclimation of Arabidopsis to nutritional phosphate deprivation. Plant Physiology 153:1112-1122. https://doi:10.1104/pp.110.153270

Hyland C, Ketterings Q, Dewig D, Stockin K, Czymmek K, Albrecht G, Geohring L (2005). Phosphorus basics - the phosphorus cycle. Agronomy Fact Sheet Series, Fact Sheet 12. Cornell University Cooperative Extension, pp 2. http://nmsp.css.cornell.edu

Idris A, Ahmed H (2012). Phosphorus sorption capacity as a guide for phosphorus availability. African Crop Science Journal 20:59-65. https://www.ajol.info/index.php/acsj/article/view/78720

Irene MU, Keith WG, Robert JK (2013). Microbial community diversity in agroforestry and grass vegetative filter strips. Agroforestry Systems 87:395-402. https://doi.org/10.2737/WO-GTR-96

Iyamuremye F, Dick RP, Baham J (1996). Organic amendments and phosphorus dynamics: ii. Distribution of soil fractions. Soil Science 161:436-443. https://doi.org/10.1097/00010694-199607000-00003

Jing JY, Rui YK, Zhang FS, Rengel Z, Shen JB (2010). Localized application of phosphorus and ammonium improves growth of maize seedlings by stimulating root proliferation and rhizosphere acidification. Field Crops Research 119:355-364. https://doi.org/10.1016/j.fcr.2010.08.005

Jones DL, Oburger E (2011). Solubilization of phosphorus by soil microorganism. In: Buenemann EK, Oberson A, Frossard E (Eds). Phosphorus in action. Springer, New York, pp 169-198. https://doi.org/10.1007/978-3-64215271-9_7

Karthikeyan AS, Varadarajan DK, Jain A, Held MA, Carpita NC, Raghothama KG (2007). Phosphate starvation responses are mediated by sugar signalling in Arabidopsis. Planta 225:907-918. https://doi.org/10.1007/s00425 006-0408-8

Khan A, Jilani G, Akhtar MS, Naqvi SMS, Rasheed M (2009). Phosphorus solubilizing bacteria: occurrence, mechanisms and their role in crop production. Journal of Agricultural and Biological Sciences 1(1):48-58.

Khan KS, Joergensen RG (2009). Changes in microbial biomass and P fractions in biogenic household waste compost amended with inorganic P fertilizers. Bioresource Technology 100:303-309. https://doi.org/10.1016/j.biortech.2008.06.002

Kraus HT, Warren SL (2000). Performance of turkey litter compost as a slow release fertilizer in containerized plant production. HortScience 35:19-21. https://doi.org/10.21273/HORTSCI.35.1.19

Kucey RMN (1983). Phosphate-solubilizing bacteria and fungi in various cultivated and virgin Alberta soils. Canadian Journal of Soil Science 63:671-678. https://doi.org/10.4141/cjss83-068

Lambers H, Shane MW, Cramer MD, Pearse SJ, Veneklaas, EJ (2006). Root structure and functioning for efficient acquisition of phosphorus: matching morphological and physiological traits. Annals of Botany 98:693-713. https://doi.org/10.1093/aob/mcl114

Larsen S (1967). Soil phosphorus. Advances in Agronomy 19:151-210. https://doi.org/10.1016/S0065-2113(08)60735$X$

Leinweber P, Turner BL, Meissner R (2002): Phosphorus. In: Haygarth PM, Jarvis SC (Eds). Agriculture, hydrology and water quality. CABI Publishing, Wallingford, UK, pp 29-55.

Li M, Welti R, Wang X (2006). Quantitative profiling of Arabidopsis polar glycerolipids in response to phosphorus starvation: roles of phospholipases D z1 and D z2 in phosphatidylcholine hydrolysis and digalactosyldiacylglycerol accumulation in phosphorus-starved plants. Plant Physiology 142:750-761. https://doi.org/10.1104/pp.106.085647

Lima-Rivera DL, Lopez-Lima D, Desgarennes D, Velázquez-Rodríguez AS, Carrion G (2016). Phosphate solubilization by fungi with nematicidal potential. Journal of Soil Science and Plant Nutrition 16 (2):507-524. http://dx.doi.org/10.4067/S0718-95162016005000042

Lindsay WL, Vlek PLG, Chien, SH (1989). Phosphate minerals. In: Dixon JB, Weed SB (Eds). Minerals in soil environment. Soil Science Society of America, Madison, WI, pp 1089-1130. https://soils.wisc.edu/facstaff/barak/temp/soil8510/notes/phosphates.html

Lo'pez-Bucio J, Cruz-Ramı'rez A, Herrera-Estrella L (2003). The role of nutrient availability in regulating root architecture. Current Opinion in Biology 6:280-287. https://doi.org/10.1016/S1369-5266(03)00035-9

Luengo C, Brigante M, Antelo J, Agenda, M (2006). Kinetics of phosphate adsorption on goethite: comparing batch adsorption and ATR-IR measurements. Journal of Colloid and Interface Science 300: 511-518. https://doi.org/10.1016/j.jcis.2006.04.015 
Lynch JP (1995). Root architecture and plant productivity. Plant Physiology 109:7-3. https://doi.org/10.1104/pp.109.1.7

Lynch JP, Brown KM (2008). Root strategies for phosphorus acquisition. In: White PJ, Hammond JP (Eds). The ecophysiology of plant-phosphorus interactions. Springer, Dordrecht, The Netherlands, pp 83-116. https://doi.org/10.1007/978-1-4020-8435-5_5

Magalhaes JV, Liu J, Guimara es CT, Lana UGP, Alves VMC, Wang Y-H, ... Shaft JE (2007) A gene in the multidrug and toxic compound extrusion (MATE) family confers aluminum tolerance in sorghum. Nature Genetics 39:1156-1161. https://doi.org/10.1038/ng2074

Mahdi S, Talat MA, Dar M, Hamid A, Ahmad L (2012). Soil phosphorus fixation chemistry and role of phosphate solubilizing bacteria in enhancing its efficiency for sustainable cropping - A review. Journal of Pure and Applied Microbiology 66:1905-1911.

Marieb EN (2008). Human anatomy and physiology. Menlo Park, CA, Benjamin/Cummings, pp 61. https://www.worldcat.org/title/human-anatomy-physiology/oclc/643185418

Marschner H (1995). Mineral nutrition of higher plants. Ed 2. Academic Press, London, pp 889. https://doi.org/10.1016/B978-0-12-473542-2.X5000-7

McDowell RW, Condron LM (2012). Phosphorus and the Winchmore trials: review and lessons learnt. New Zealand Journal of Agriculture Research 55:119-132. https://doi.org/10.1080/00288233.2012.662899

McDowell RW, Koopmans GF (2006). Assessing the bioavailability of dissolved organic phosphorus in pasture and cultivated soils treated with different rates of nitrogen fertilizer. Soil Biology and Biochemistry 38:61-70. https://doi.org/10.1016/j.soilbio.2005.03.026

McGill WB, Cole CV (1981). Comparative aspects of cycling of organic C, N, S and P thorough soil organic-matter. Geoderma 26:267-286. https://doi.org/10.1016/0016-7061(81)90024

Mullins G (2019). Phosphorus, agriculture \& the environment. Virginia Cooperative Extension, pp 16. Retrieved 2019 August 8 from https://www.pubs.ext.vt.edu/424/424-029/424-029.html

Nacry P, Canivenc G, Muller B, Azmi A, Van Onckelen H, Rossignol M, Doumas P (2005). A role for auxin redistribution in the responses of the root system architecture to phosphate starvation in Arabidopsis. Plant Physiology 138:2061-2074. https://doi.org/10.1104/pp.105.060061

Negassa W, Leinweber P (2009). How does the Hedley sequential phosphorus fractionation reflect impacts of land use and management on soil phosphorus: a review. Journal of Plant Nutrition and Soil Science 172:305-325. https://doi.org/10.1002/jpln.200800223

Neumann G, Massonneau A, Martinoia E, Ro“mheld V (1999). Physiological adaptations to phosphorus deficiency during proteoid root development in white lupin. Planta 208:373-382. https://doi.org/10.1007/s004250050572

Neumann G, Ro"mheld V (2002). Root-induced changes in the availability of nutrients in the rhizosphere. In: Waisel Y, Eshel A, Kafkafi U (Eds). Plant roots, the hidden half. Ed 3. Marcel Dekker, Inc., New York, pp 617-649. https://doi.org/10.1093/aob/mcf252

Newman EI (1995). Phosphorus inputs to terrestrial ecosystems. Journal of Ecology 83:713-726. https://doi.org/10.2307/2261638

Oelkers EH, Valsami-Jones E (2008). Phosphate mineral reactivity and global sustainability. Elements 4:83-87. https://doi.org/10.12691/wjar-3-2-6

Ohtake H, Wu H, Imazu K, Ambe Y, Kato J, Kuroda A (1996). Bacterial phosphonate degradation, phosphite oxidation and polyphosphate accumulation. Resources, Conservation and Recycling 18(1-4):125-134.

Ordoñez YM, Fernandez BR, Lara LS, Rodriguez A, Uribe-Vélez D, Sanders IR (2016). Bacteria with phosphate solubilizing capacity alter mycorrhizal fungal growth both inside and outside the root and in the presence of native microbial communities. PLoS ONE 11(6):e0154438. https://doi.org/10.1371/journal.pone.0154438

Osmont KS, Sibout R, Hardtke CS (2007). Hidden branches: developments in root system architecture. Annual Reviews of Plant Biology 58:93-113. https://doi.org/10.1146/annurev.arplant.58.032806.104006

Padmavathi P (2015). Optimization of phosphate solubilization by Aspergillus niger using plackett-burman and response surface methodology. Journal of Soil Science and Plant Nutrition 15(3):781-793. https://doi.org/10.4067/S0718-95162015005000053

Parfitt RL (1989). Phosphate reactions with natural allophone, ferrihydrite and goethite. Journal of Soil Science 40:359369. https://doi.org/10.1111/j.1365-2389.1989.tb01280.x 
Pavinato PS, Martin, TN, Mondardo JT, Marangon RJ (2015). Phosphorus availability and plant production in a Ferralsol from South Brazil. In: 19 ${ }^{\text {th }}$ World Congress of Soil Science. Soil Solutions for a Changing World, 1-6 August 2010, Brisbane, Australia, pp 4.

Pierzynski GM, McDowell RW, Sims JT (2005) Chemistry, cycling, and potential movement of inorganic phosphorus in soils. In: JT Sims, AN Sharpley (Eds.), Phosphorus: agriculture and the environment. American Society of Agronomy, Crop Science Society of America, Soil Science Society of America, Inc., Madison, WI, pp 53-86. https://doi.org/10.2134/agronmonogr46.c3

Pratt J, Boisson A-M, Gout, E, Bligny R, Douce R, Aubert S (2009). Phosphate (Pi) starvation effect on the cytosolic Pi concentration and Pi exchanges across the tonoplast in plant cells: an in vivo31P-nuclear magnetic resonance study using methylphosphonate as a Pi analog. Plant Physiology 151:1646-1657. https://doi.org/10.1104/pp.109.144626

Quiquampoix H, Mousain D (2005). Enzymatic hydrolysis of organic phosphorus. In: Turner BL, Frossard E, Baldwin D (Eds). Organic phosphorus in the environment. CAB International, Wallingford, UK, pp 89-112. https://doi.org/10.1079/9780851998220.0089

Raghotama KG (2005). Phosphorus and plant nutrition: An overview. In: Sims JT, Sharpley AN (Eds). Phosphorus: agriculture and environment. Madison, Wisconsin, USA, pp 355-378.

Raghothama KG (1999). Phosphate acquisition. Annual Review of Plant Physiology and Plant Molecular Biology 50:665693. https://doi.org/10.1146/annurev.arplant.50.1.665

Reasons T (2008). Root branching responses to phosphate and nitrate. Current Opinion in Plant Biology 11:82-87. https://doi.org/10.1016/j.pbi.2007.10.003

Reddy KR, O’Connor GA, Schelske CL (Eds) (1999). Phosphorus biogeochemistry in sub-tropical ecosystems. Boca Raton, FL: Lewis, pp 728. https://trove.nla.gov.au/work/32648204

Richardson AE, Barea JM, McNeill AM, Prigent-Combaret C (2009). Acquisition of phosphorus and nitrogen in the rhizosphere and plant growth promotion by microorganism. Plant Soil 321:305-339. https://doi.org/10.1007/s11104-009-9895-2

Richardson AE, George TS, Hens M, Simpson RJ (2005). Utilization of soil organic phosphorus by higher plants. In: Turner BL, Frossard E, Baldwin D (Eds). Organic phosphorus in the environment. CAB International, Wallingford, UK, pp 165-184.

Rodríguez H, Fraga R, Gonzalez T, Bashan Y (2006). Genetics of phosphate solubilization and its potential applications for improving plant growth-promoting bacteria. Plant and Soil 287:15-21. https://doi.org/10.1007/s11104-0069056-9

Rossolini GM, Shippa S, Riccio ML, Berlutti F, Macaskie LE (1998). Bacterial nonspecific acid phosphatases: physiology, evolution, and use as tools in microbial biotechnology. Cellular and Molecular Life Sciences 54:833-850.

Rouached H, Arpat AB, Poirier Y (2010). Regulation of phosphate starvation responses in plants: signaling players and cross-talks. Molecular Plant 3:288-299. https://doi.org/10.1093/mp/ssp120

Rubaek GH, Sibbesen E (1993). Resin extraction of labile, soil organic phosphorus. European Journal of Soil Science 44 (3):467-478. https://doi.org/10.1111/j.1365-2389.1993.tb00469.x

Schoenau JD, Adderley R, Holm C, Baan T, King M, Grevers P, ... Moulin A (2007). Tillage and phosphorus availability. In: Saskatchewan soils and crops workshop. University of Saskatchewan, Saskatoon, SK, Canada pp 15. http://hdl.handle.net/10388/9359

Shand CA, Macklon AES, Edwards AC, Smith S (1994). Inorganic and organic P in soil solutions from three upland soils. Plant Soil 159:255-264. https://doi.org/10.1007/BF00009288

Sharma SB, Sayyed RZ, Trivedi MH, Gobi, TA (2013). Phosphate solubilizing microbes: sustainable approach for managing phosphorus deficiency in agricultural soils. SpringerPlus 2:587. https://doi.org/10.1186/2193-1801-2587

Shin H, Shin HS, Dewbre GR, Harrison MJ (2004). Phosphate transport in Arabidopsis: Pht 1;1 and Pht 1;4 play a major role in phosphate acquisition from both low- and high-phosphate environments. Plant Journal 39:629-642. https://doi.org/10.1111/j.1365-313X.2004.02161.x

Simpson M, McLenaghen RD, Chirino-Valle I, Condron L (2012). Effects of long-term grassland management on the chemical nature and bioavailability of soil phosphorus. Biology and Fertility of Soils 48:607-611. https://doi.org/10.1007/s00374-011-0661-2

Smil V (1997). Cycles of life. Civilization and the biosphere. Nature 386(6620):35 
Smil V (2005). Carbon nitrogen sulfur. Human interference in grand biospheric cycles. Smil V (Ed). New York, Plenum, pp 460. https://www.springer.com/gp/book/9781468488418

Sposito G (1986). Distinguishing adsorption from surface precipitation. American Chemical Society, Washington DC, USA, pp 217-228. https://doi.org/10.1021/bk-1987-0323.ch011

Stark JC, Westermann DT (2003). Nutrient Management. In: Stark JC, Love SL (Eds). Potato production systems. University of Idaho Agricultural Communications, Moscow, pp 15-135. https://doi.org/10.1007/978-3-03039157-7_8

Stefanovic A, Ribot C, Rouached H, Wang Y, Chong J, Belbahri L, ... Poirier Y (2007). Members of the PHO1 gene family show limited functional redundancy in phosphate transfer to the shoot, and are regulated by phosphate deficiency via distinct pathways. Plant Journal 50:982-994. https://doi.org/10.1111/j.1365-313X.2007.03108.X

Stevenson F (2005). Cycles of soil: carbon, nitrogen, phosphorus, sulfur, micronutrients. John Wiley and Sons, New York, pp $140 . \quad$ https://www.wiley.com/enus/Cycles+of + Soils\%3A+Carbon\%2C+Nitrogen\%2C+Phosphorus\%2C+Sulfur\%2C+Micronutrients\%2C+2 nd+Edition-p-9780471320715

Stewart WM, Hammond LL, Van Kauwenbergh SJ (2005). Phosphorus as a natural resource. In: Sims JT and Sharpley AN (Editors). Phosphorus: agriculture and environment. Madison, Wisconsin, USA, pp 3-22. https://doi.org/10.2134/agronmonogr46.c1

Suleman M, Yasmin S, Rasul M, Yahya M, Atta BM, Mirza MS (2018). Phosphate solubilizing bacteria with glucose dehydrogenase gene for phosphorus uptake and beneficial effects on wheat. PLoS ONE 13(9):e0204408. https://doi.org/10.1371/journal.pone.0204408

Surange S, Wollum G, Kumar N, Nautiyal C (1995). Characterization of Rhizobium from root nodules of leguminous trees growing in alkaline soils. Canadian Journal of Microbiology 43:891-894. https://doi.org/10.1139/m97-130

Tak H, Ahmad F, Babalola OO, Inam A (2012). Growth, photosynthesis and yield of chickpea as influenced by urban wastewater and different levels of phosphorus. International Journal of Plant Research 2:6-13. https://doi.org/10.5923/j.plant.20120202.02

Tate KR (1984). The biological transformation of $\mathrm{P}$ in soil. Plant and Soil 76:245-256. https://doi.org/10.1007/BF02205584

Tening AS, Foba-Tendo JS, Yakum-Ntaw SY, Tchuenteu F (2013). Phosphorus fixing capacity of a volcanic soil on the slope of Mount Cameroon. Agriculture and Biology Journal of North America 4(3):166-174. https://doi.org/10.5251/abjna.2013.4.3.166.174

Tiessen H (1995). Phosphorus in the global environment: transfers, cycles and management. Wiley, Chichester pp 1-7. https://doi.org/10.1007/978-1-4020-8435-5_1

Tipping E, Benham S, Boyle JF, Crow P, Davies J, Fischer U, ... Toberman H (2014). Atmospheric deposition of phosphorus to land and freshwater. Environmental Science: Processes and Impact 16:1608-1617. https://doi.org/10.1039/C3EM00641G

Turner BL, Condron L, Richardson SJ, Peltzer DA, Allison VJ (2007). Soil organic phosphorus transformations during pedogenesis. Ecosystems 10(7):166-1181. https://doi.org/1007/s10021-0079086-Z

Turner BL, Mahieu N, Condron LM, Chen CR (2005). Quantification and bioavailability of scyllo-inositol hexakisphosphate in pasture soils. Soil Biology and Biochemistry 37:2155-2158. https://doi.org/10.1016/j.soilbio.2005.03.005

Turner BL, Papha'zy MJ, Haygarth PM, McKelvie ID (2002). Inositol phosphates in the environment. Philosophical Transactions of the Royal Society B: Biological Sciences 357:449-469. https://doi.org/10.1098/rstb.2001.0837

Turner BL, Richardson AE, Mullaney EJ (2007). Inositol phosphates: linking agriculture and the environment. CAB International, Wallingford, UK, pp 304.

Turner, B. L. and Newman, S. (2005). Phosphorus cycling in wetland soils. Journal of Environmental Quality 34(5):19211929. https://doi.org/10.2134/jeq2005.0060

Vance CP (2008). Plants without arbuscular mycorrhizae. In: White PJ, Hammond JP (Eds). The ecophysiology of plantphosphorus interactions. Springer, Dordrecht, The Netherlands, pp 117-142. https://www.springer.com/gp/book/9781402084348

Vance CP, (2010). Quantitative trait loci, epigenetics, sugars, and microRNAs: quaternaries in phosphate acquisition and use. Plant Physiology 154:582-588. https://doi.org/10.1104/pp.110.161067

Vance CP, Uhde-Stone C, Allan DL (2003). Phosphorus acquisition and use: critical adaptations by plants for securing a non-renewable resource. New Phytologist 157:423-447. https://doi.org/10.1046/j.1469-8137.2003.00695.x 
Vazquez P, Holguin P, Puente H, Lopez-Cortes ME, Bashan Y (2000). Phosphate-solubilizing microorganisms associated with the rhizosphere of mangroves in a semiarid coastal lagoon. Biology and Fertility of Soils 30:460-468. https://doi.org10.1007/s003740050024

Verma SL (2013). Effect of compost on soil phosphorus availability. Soils. School of Agriculture, Food and Vine. The University of Adelaide, Australia pp 141.

Versaw WK, Harrison MJ (2002). A chloroplast phosphate transporter, PHT2;1, influences allocation of phosphate within the plant and phosphate-starvation responses. Plant Cell 14:1751-1766. https://doi.org/10.1105/tpc.002220

Walker TW, Syers JK (1976). The fate of phosphorus during pedogenesis. Geoderma 15:1-19. https://doi.org/10.1016/0016-7061(76)90066-5

Wang BL, Shen JB, Zhang WH, Zhang FS, Neumann G (2007). Citrate exudation from white lupin induced by phosphorus deficiency differs from that induced by aluminum. New Phytologist 176:581-589. https://doi.org/10.1111/j.1469-8137.2007.02206.x

Wang BL, Tang XY, Cheng LY, Zhang AZ, Zhang, WH, Zhang FS, ... Vance CP (2010). Nitric oxide is involved in phosphorus deficiency-induced cluster-root development and citrate exudation in white lupin. New Phytologist 187:1112-1123. https://doi.org/10.1111/j.1469-8137.2010.03323.x

Wang LJ, Nancollas GH (2008). Calcium orthophosphates: crystallization and dissolution. Chemical Reviews 108:46284669. https://doi.org/10.1021/cr0782574

Westheimer FH (2007). Why nature chose phosphates. Science 235:1173-1177. https://doi.org/10.1126/science.2434996

Wissuwa M, Mazzola M, Picard C (2009). Novel approaches in plant breeding for rhizosphere-related traits. Plant Soil 321:409-430. https://doi.org/10.1007/s11104-008-9693-2

Wolfe GV (1992). Global biogeochemical cycles. (Vol. 50). Butcher SS, Charlson RJ, Orians GH (Eds.). London: Academic Press.

Woodwell GM, Mackenzie FT (Eds) (1995). Biotic feedbacks in the global climatic system. New York, Oxford Univ. Press pp 436. https://global.oup.com/academic/product/biotic-feedbacks-in-the-global-climatic-system$9780195086409 ?$ ?c $=$ us\&lang=en\&

Yu B, Xu CC, Benning C (2002). Arabidopsis disrupted in SQD2 encoding sulfolipid synthase is impaired in phosphatelimited growth. Proceedings of National Academy of Sciences USA 99:5732-5737. https://doi.org/10.1073/pnas.082696499

Yu W, Ding X, Xue S, Li S, Liao X, Wang R (2013). Effects of organic-matter application on phosphorus adsorption of three soil parent materials. Journal of soil science and Plant Nutrition 13 (4):1-13. https://doi.org/10.4067/S0718-95162013005000079

Zaharah AR, Bah AR (1997). Effect of green manures on P solubilization and uptake from phosphate rocks. Nutrient Cycling in Agroecosystems 48:247-255. https://doi.org/10.1023/A:1009734122858

Zhan F, Shen J, Zhang J, Zuo Y, Li L, Chen X (2010). Rhizosphere processes and management for improving nutrient use efficiency and crop productivity: implications for China. Advances in Agronomy 107:1-32. https://doi.org/10.1016/s0065-2113(10)07001-x

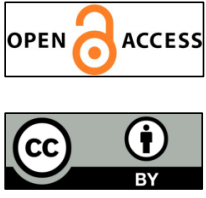

The journal offers free, immediate, and unrestricted access to peer-reviewed research and scholarly work. Users are allowed to read, download, copy, distribute, print, search, or link to the full texts of the articles, or use them for any other lawful purpose, without asking prior permission from the publisher or the author.

License - Articles published in Notulae Scientia Biologicae are Open-Access, distributed under the terms and conditions of the Creative Commons Attribution (CC BY 4.0) License.

(c) Articles by the authors; SHST, Cluj-Napoca, Romania. The journal allows the author(s) to hold the copyright/to retain publishing rights without restriction. 